\title{
Inhibiting the Cannabinoid Catabolic Enzyme MAGL to Potentiate the Anti-Arthritic Properties of the Synthetic Glucocorticoid Dexamethasone
}

\author{
Sara R. Nass
}

Follow this and additional works at: https://researchrepository.wvu.edu/etd

\section{Recommended Citation}

Nass, Sara R., "Inhibiting the Cannabinoid Catabolic Enzyme MAGL to Potentiate the Anti-Arthritic Properties of the Synthetic Glucocorticoid Dexamethasone" (2017). Graduate Theses, Dissertations, and Problem Reports. 6298.

https://researchrepository.wvu.edu/etd/6298

This Dissertation is protected by copyright and/or related rights. It has been brought to you by the The Research Repository @ WVU with permission from the rights-holder(s). You are free to use this Dissertation in any way that is permitted by the copyright and related rights legislation that applies to your use. For other uses you must obtain permission from the rights-holder(s) directly, unless additional rights are indicated by a Creative Commons license in the record and/ or on the work itself. This Dissertation has been accepted for inclusion in WVU Graduate Theses, Dissertations, and Problem Reports collection by an authorized administrator of The Research Repository @ WVU.

For more information, please contact researchrepository@mail.wvu.edu. 
Inhibiting the Cannabinoid Catabolic Enzyme MAGL to Potentiate the Anti-Arthritic Properties of the Synthetic Glucocorticoid Dexamethasone

\author{
Sara R. Nass, M.S. \\ Dissertation submitted to the Eberly College of Arts and Sciences at \\ West Virginia University \\ in partial fulfillment of the requirements for the degree of \\ Doctor of Philosophy in Psychology/Behavioral Neuroscience
}

Steven G. Kinsey, Ph.D., Chair
Melissa D. Blank, Ph.D.
Cole Vonder Haar, Ph.D.
Christina L. Duncan, Ph.D.
Lisa J. Robinson, Ph.D.
Department of Psychology

Morgantown, WV

2017

Keywords: Rheumatoid arthritis, collagen induced arthritis, endocannabinoid, MAGL, steroid, dexamethasone

Copyright 2017 Sara R. Nass 


\section{Abstract \\ Inhibiting the Cannabinoid Catabolic Enzyme MAGL to Potentiate the Anti-Arthritic Properties of the Synthetic Glucocorticoid Dexamethasone}

\section{Sara R. Nass}

Rheumatoid arthritis (RA, Table 1) is the most common type of inflammatory arthritis, and is characterized by swelling, inflammation, pain, and destruction of the synovial joints (i.e., knees, elbows, wrists, hips, and fingers). Glucocorticoid receptor agonists are a type of steroid hormone and are among the most common treatments for inflammatory arthritis because of their powerful anti-inflammatory effects. However, harmful side effects are associated with these glucocorticoids (GCs), including increasing patients' vulnerability to infections. Cannabinoids (i.e., cannabis-like signaling molecules) exert anti-inflammatory and analgesic effects with limited side effects compared to traditional immunosuppressants making them excellent targets for the development of new arthritic therapeutics. For example, in mice, selective inhibition of the cannabinoid enzyme monoacylglycerol lipase (MAGL) reduces acute inflammatory pain and edema. Dual administration of drugs are promising novel treatments because it allows lower doses of drugs to attenuate pain and inflammation, while limiting side effects. Combined administration of an endocannabinoid enzyme inhibitor and nonsteroidal anti-inflammatory drug reduces neuropathic and acute pain. Similarly, inflammatory arthritis is reduced by a GC administered with an anti-inflammatory cytokine (i.e., immune system signaling molecule) in mice. Given the anti-inflammatory properties of MAGL inhibition, it is plausible that MAGL inhibition will increase the analgesic and anti-inflammatory effects of a steroid treatment, perhaps reducing the negative side effects of the steroid. Therefore, the goals of the present studies were to determine the analgesic and anti-inflammatory efficacy of (1) the MAGL inhibitor JZL184; (2) the glucocorticoid steroid dexamethasone (DEX); and (3) the combined administration of both JZL184 and DEX. To these ends, we used the collagen-induced arthritis (CIA) mouse model. We found that, although both JZL184 and DEX significantly attenuated proinflammatory cytokine levels in the paws of CIA mice, only DEX decreased pain-related behaviors and paw swelling. Combined administration of a sub-effective dose both drugs was ineffective overall. 
Non-standard Abbreviations.....................................................................................

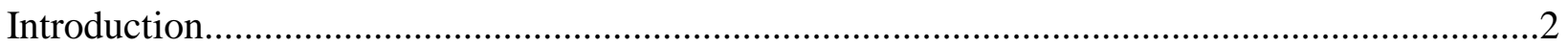

The Immune System........................................................................................

Inflammatory Response in Rheumatoid Arthritis....................................................5

Current Rheumatoid Arthritis Treatments..................................................................6

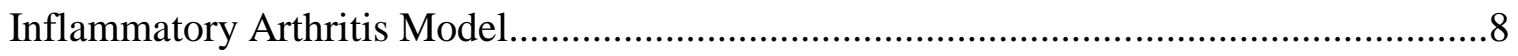

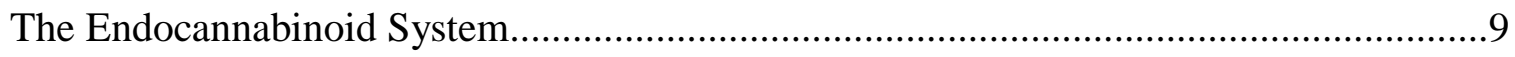

Cannabinoids in Inflammatory Arthritis......................................................... 11

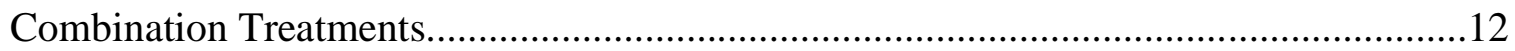

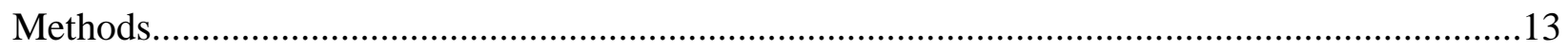

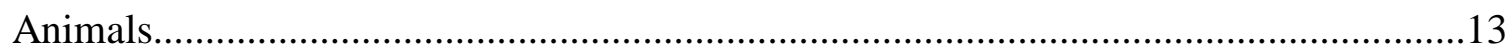

Collagen Induced Arthritis (CIA) Inflammatory Arthritis.........................................13

Paw Edema and Clinical Scoring.................................................................. 14

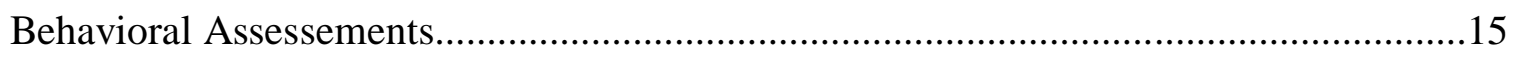

Cytokine and Myeloperoxidase Enzyme-Linked Immunosorbent Assay.......................17

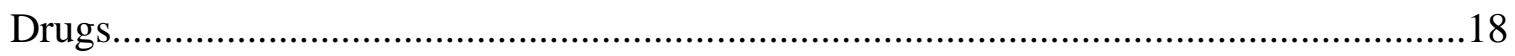

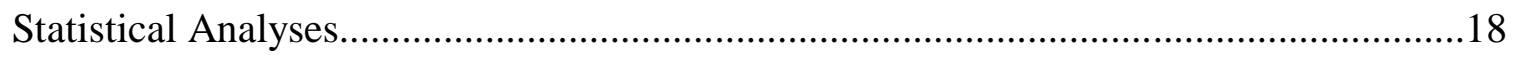

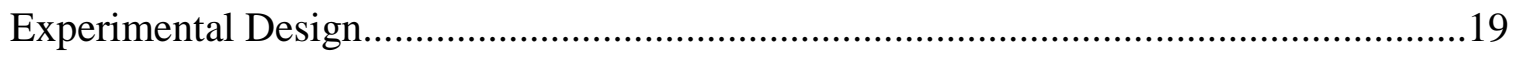


Results.

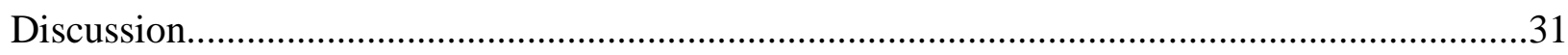

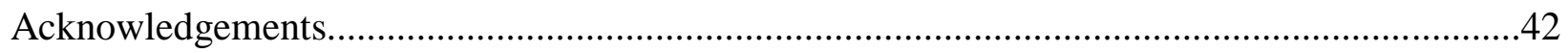

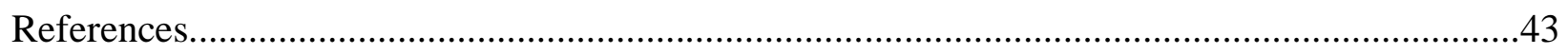

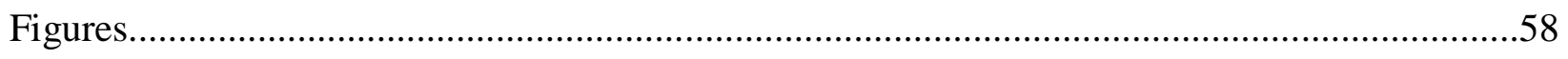

Appendix A. Grip strength as a measure of CIA-induced loss of paw function........................68

Appendix B. Anti-arthritic effects of CB2 agonism in CIA and CFA-induced arthritis models...72

Appendix C. Collagen Antibody-induced Arthritis Model.................................................76 


\begin{tabular}{|c|c|}
\hline Abbreviation & Full Term \\
\hline $2-A G$ & 2-arachidonoylglycerol \\
\hline anandamide & $\mathrm{N}$-arachidonoylethanolamine \\
\hline $\mathrm{CB}_{1}$ & cannabinoid receptor one \\
\hline $\mathrm{CB}_{2}$ & cannabinoid receptor two \\
\hline CFA & complete Freund's adjuvant \\
\hline CIA & collagen induced arthritis \\
\hline CNS & central nervous system \\
\hline DEX & dexamethasone \\
\hline DMARDs & disease-modifying antirheumatic drugs \\
\hline FAAH & fatty acid amide hydrolase \\
\hline FLS & fibroblast-like synoviocytes \\
\hline GCs & glucocorticoids \\
\hline IFA & incomplete Freund's adjuvant \\
\hline IL & interleukin \\
\hline IL-1 $\beta$ & interleukin-1beta \\
\hline IL-10 & interleukin-10 \\
\hline IL-17 & interleukin-17 \\
\hline IL-6 & interleukin-6 \\
\hline MAGL & monoacylglycerol lipase \\
\hline MHC & major histocompatibility complex \\
\hline MMP & matrix metalloproteinase \\
\hline MPO & myeloperoxidase \\
\hline RA & rheumatoid arthritis \\
\hline Th1 & Type $1 \mathrm{~T}$ helper cells \\
\hline TH17 & $\mathrm{T}$ helper 17 cells \\
\hline $\mathrm{THC}$ & $\Delta 9$-tetrahydrocannabinol \\
\hline $\mathrm{TNF} \alpha$ & tumor necrosis factor alpha \\
\hline Treg & regulatory $\mathrm{T}$ cells \\
\hline
\end{tabular}

Table 1. Non-standard abbreviations. 


\section{Introduction}

Rheumatoid Arthritis (RA) is a debilitating chronic joint disorder that causes mood disturbances and decreases activity. The most common features are swelling, inflammation, pain, and erosion of the synovial joints (Firestein, 2003). RA pain is primarily induced by chronic inflammation, and has a higher correlation with functional disability compared to joint destruction alone, indicating pain is a greater predictor for RA outcome (Sokka, Kankainen, \& Hannonen, 2000). Chronic inflammation and tissue damage in RA is causes by a failure of the host's immune system to discriminate between self and non-self tissue, thus RA is an autoimmune disorder (Lindstrom \& Robinson, 2010). The following sections cover a primer on the immune system and the inflammatory response as it relates to RA, followed by background on the endocannabinoid system, and rationale for combined targeting of both immune and cannabinoid systems to combat inflammatory arthritis in the proposed mouse model.

\section{The Immune System}

Although the immune system protects the host from pathogens (e.g., viruses and bacteria), an inflammatory response can also be initiated against self-tissue (i.e., autoimmunity) or non-threatening environmental stimuli (e.g., allergy). The two main branches of the immune system are innate and adaptive immunity. Innate immunity is non-specific and mounts a swift immune response in a consistent manner, even after multiple presentations of the same pathogen (Abbas, Litchman, \& Pober, 2002). In contrast, a specific response to the presence of pathogens is developed by adaptive (i.e., acquired) immunity. A distinct response and memory for individual pathogens is acquired, so a quicker and more intense response can be mounted after repeat exposure. Adaptive immunity is essential in vaccinations, but also autoimmune disorders such as RA. After immunization with a weakened or killed pathogen, adaptive immunity 
develops memory, causing a more powerful immune response when the pathogen is encountered in the future (Abbas et al., 2002). The adaptive immune system is normally nonreactive to tissues originating from the host. However, this tolerance to self-tissue can break down and lead to autoimmunity (Lindstrom \& Robinson, 2010).

Although there are many different cells involved in the inflammatory response, only the cells most relevant to the proposed project will be discussed here (see Figure 1). The short-lived innate leukocytes (i.e., white blood cells), neutrophils, are the first cells to be activated during the inflammatory response and attract macrophages and dendritic cells to the site of inflammation (Nathan, 2006). Neutrophils express a substantial amount of the enzyme myeloperoxidase (MPO), which can be analyzed as an indirect measure of neutrophil activity (Al-Abd et al., 2014). Monocytes are immature innate leukocytes that circulate in the blood and differentiate into macrophages when recruited to inflamed tissue (Abbas et al., 2002). Macrophages release pro-inflammatory cytokines (i.e., the "hormones" of the immune system), and engage in phagocytosis (i.e., engulfing harmful molecules) and antigen presentation (Boissier, Semerano, Challal, Saidenberg-Kermanac'h, \& Falgarone, 2012). Dendritic cells bridge the gap between innate and adaptive immunity by engulfing antigens (i.e., substances that induce antibody production) and presenting them via major histocompatibility complex (MHC) class II molecules to $\mathrm{T}$ cells of the adaptive immune system. Activated helper CD4+T cells then migrate from lymph nodes to the site of inflammation. The Type $1 \mathrm{~T}$ helper (Th1) and T helper 17 (Th17) cell subtypes are considered proinflammatory and activate leukocytes; whereas regulatory T cells (Tregs) release anti-inflammatory cytokines (Rabb, 2002). B cells of the adaptive immune system release antibodies that bind to antigens (Rabb, 2002). 


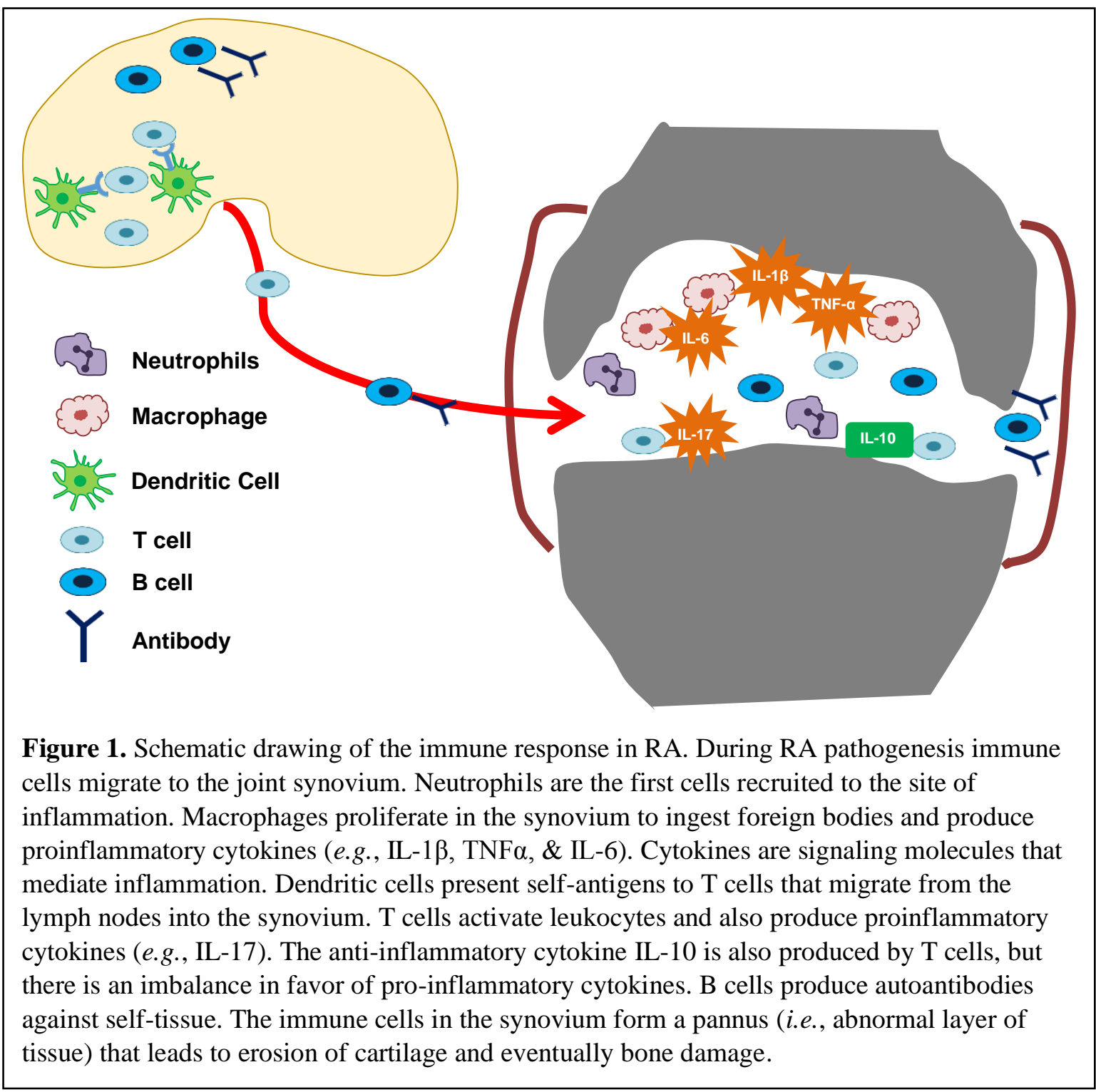

Cytokines are signaling molecules that modulate the immune response. Cytokines are pleiotropic (i.e., activate a variety of leukocytes) and redundant (i.e., different cytokines have similar effects). Proinflammatory cytokines stimulate leukocyte activation, to eliminate antigens and synthesize more cytokines. The pro-inflammatory cytokines tumor necrosis factor alpha

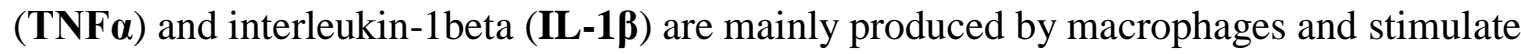
leukocytes; whereas interleukin-17A (IL-17A) is produced by Th17 cells and induces proinflammatory cytokine production (Boissier et al., 2012; Shahrara, Huang, Mandelin, \& Pope, 2008). The proinflammatory cytokine interleukin-6 (IL-6) is released from a variety of 
leukocytes and induces antibody production (Boissier et al., 2012). Some cytokines have predominantly anti-inflammatory effects. For example, the anti-inflammatory cytokine interleukin-1 (IL-10) is produced by Treg cells and reduces inflammation and regulates the inflammatory response, helping return the host to homeostasis after pathogen elimination (Chen et al., 2012).

\section{Inflammatory Response in Rheumatoid Arthritis}

Although the exact etiology of RA is not well understood, the progression of inflammation involves the innate and adaptive immune systems (see Figure 1). The synovium (i.e., the soft tissue lining of synovial joints, such as knuckles) is the main site of inflammation and tissue destruction in RA (Smith, 2011). Genetic susceptibility to RA is associated with specific variations of the genes that encode for MHC class II molecules expressed on antigen presenting cells (e.g., dendritic cells and macrophages) (Roudier, 2006). There is an increase in activated macrophages within the RA synovium that release pro-inflammatory cytokines (e.g., TNF $\alpha$, IL-1 $\beta$, and IL-6) (McInnes \& Schett, 2011). During RA pathogenesis, self-tissues are presented by MHC class II molecules on dendritic cells and macrophages to helper T cells. Within the synovium and blood of RA patients, proinflammatory Th1 and Th17 helper T cell subtypes increase in number, while anti-inflammatory Treg helper T cells decrease (Chen et al., 2012; Shahrara et al., 2008). Immune memory develops when proinflammatory cytokines stimulate cells to produce autoantibodies (e.g., rheumatoid factor) against self-tissue, resulting in further inflammation in the synovium (Takemura, Klimiuk, Braun, Goronzy, \& Weyand, 2001). Thus, the initial innate immune response to self-tissue becomes an acquired immune response to self-tissue that generally targets tissues in the synovial joints. 
Within the RA synovium there is an abundance of the proinflammatory cytokines TNF $\alpha$,

IL-1 $\beta$, IL-6, and IL-17 (McInnes \& Schett, 2007; Shahrara et al., 2008). These cytokines are also expressed in the serum of RA patients, but not healthy volunteers, indicating an upregulation of proinflammatory cytokines throughout the body (Chen et al., 2012). The presence of IL-10 in RA serum and joints indicates a failure of the immune system to keep RA inflammation in check (Chen et al., 2012). Proinflammatory cytokines induce inflammatory pain by decreasing nociceptor (i.e., free nerve ending that acts as a receptor for pain) activation threshold (Kidd \& Urban, 2001).

In addition to leukocytes, fibroblast-like synoviocytes (FLS) are mesenchymal cells that proliferate and adhere to the cartilage in RA joints. FLS activated by TNF $\alpha$ and IL-1 $\beta$ aggressively destroy RA joints by releasing more proinflammatory cytokines and matrix metalloproteinase (MMPs) that degrade the cartilage extracellular matrix (Karouzakis, Neidhart, Gay, \& Gay, 2006). Chronic inflammation and the release of cartilage degrading MMPs causes the synovium to become hyperplastic and develop pannus (i.e., an abnormal tissue layer), eventually leading to cartilage destruction and bone erosion (Karouzakis et al., 2006; McInnes \& Schett, 2011).

\section{Current Rheumatoid Arthritis Treatments}

Reducing RA symptoms typically involves decreasing joint inflammation and the resulting pain perception. Immunosuppressants, including disease-modifying antirheumatic drugs (DMARDs), glucocorticoids (GCs), and biologic therapies are the most common pharmacological treatments used to slow RA progression (Singh et al., 2016). However, immunosuppressants can induce aversive side effects, and patients often experience pain despite 
improvement in inflammation (Lee, 2013). For example, DMARDs, such as methotrexate reduce pain in addition to inflammation, but need to be administered early to exert analgesic effects. Efficacy of DMARDs as analgesics decreases when introduced even just twelve months after diagnosis (Nell et al., 2004). Biologic therapies suppress specific components of the immune system. However, they are associated with higher annual healthcare expenditure compared to other immunosuppressants, and in some patients are ineffective at slowing the progression of joint damage or reducing symptoms (Walsh \& McWilliams, 2012).

Steroids are clinically useful at quickly reducing inflammation and associated pain, but can induce harmful metabolic side effects (Singh et al., 2016). GCs are steroid hormones that are produced from cholesterol in the cortex of the adrenal glands. GCs bind to cytosolic GC receptors within cells to regulate gene expression. Steroids decrease immune cell recruitment through inhibition of the transcription of genes that encode proinflammatory cytokines (Coutinho \& Chapman, 2011). In peripheral blood mononuclear cells taken from RA patients, GCs inhibit the production of the proinflammatory cytokines TNF $\alpha$, IL-1 $\beta$, IL-6, and IL-17 (Colin et al., 2010; Schlaghecke, Beuscher, Kornely, \& Specker, 1994). Due to their potent anti-inflammatory effects, synthetic GCs such as prednisone are effective at treating RA and other inflammatory diseases. However, GCs also activate expression of genes involved in metabolic processes (Coutinho \& Chapman, 2011). Therefore, long term use increases the risk of serious aversive effects, including adrenal insufficiency, osteoporosis, diabetes, and cardiovascular risk (Ravindran, Rachapalli, \& Choy, 2009). Due to the aforementioned side effects, GCs are mainly administered at low doses for maintenance therapy, or at high doses for short term use to reduce inflammation during "flare-ups" (J. F. Ferreira, Ahmed Mohamed, \& Emery, 2016). Although immunosuppressive treatments are effective at slowing disease progression they can lead to 
serious side effects because they dampen the immune response. The main obstacle in immunosuppressant use is the increased susceptibility to infections, such as tuberculosis and hepatitis (Furst, 2010).

\section{Inflammatory Arthritis Model}

Preclinical animal models of inflammatory arthritis are used to study RA mechanisms and treatments. The collagen-induced arthritis (CIA) model of inflammatory arthritis is the most extensively used animal model to research the pathogenesis of RA progression and potential novel treatments (Brand, Latham, \& Rosloniec, 2007; Williams, Feldmann, \& Maini, 1992). CIA is induced by immunizing mice with a mixture of type II collagen and complete Freund's adjuvant (CFA) (Brand et al., 2007; Kinsey, Naidu, Cravatt, Dudley, \& Lichtman, 2011b). Mice will develop anti-collagen antibodies and three to seven weeks after the initial immunization swelling and redness develop in one or more paws (Brand et al., 2007). Although the development of CIA is accelerated compared to RA, the pathogenesis of both is perpetuated by synovial infiltration of neutrophils as measured by the enzyme myeloperoxidase (MPO) (Al-Abd et al., 2014), autoreactive lymphocytes (i.e., T cells and B cells) (Seki et al., 1988; Svensson, Jirholt, Holmdahl, \& Jansson, 1998), activation of macrophages and FLS (Holmdahl, Tarkowski, \& Jonsson, 1991; Nishioku et al., 2012), and increased proinflammatory cytokine production (e.g., TNFa, IL-1 $\beta$, and IL-6) (Rioja, Bush, Buckton, Dickson, \& Life, 2004). Similar to RA, the inflammatory response and synovial pannus in CIA eventually leads to cartilage destruction and joint damage (Asquith, Miller, McInnes, \& Liew, 2009; Brand et al., 2007). Thus, CIA and human inflammatory arthritis are mechanistically linked. 


\section{The Endocannabinoid System}

Cannabinoid agonists, such as $\Delta^{9}$-tetrahydrocannbinol (THC), the main psychoactive component of Cannabis, bind to and activate the G-protein-coupled receptors, cannabinoid receptor $1\left(\mathbf{C B}_{1}\right)$ and cannabinoid receptor $2\left(\mathbf{C B}_{2}\right)$ (Mechoulam \& Parker, 2013). $\mathrm{CB}_{1}$ mediates the central nervous system (CNS) effects of cannabinoids (e.g., pain, hypothermia, and cognitive and behavioral deficits) and is expressed throughout the body, including in the synovium of RA patients and on FLS (Crowe, Nass, Gabella, \& Kinsey, 2014; Gui et al., 2014; Richardson et al., 2008). On the other hand, $\mathrm{CB}_{2}$ is expressed mainly on immune cells, but is also expressed at low levels in the CNS, including on activated microglia (i.e., the macrophages of the CNS) (Cabral, Raborn, Griffin, Dennis, \& Marciano-Cabral, 2008). In the RA synovium, $\mathrm{CB}_{2}$ is expressed on macrophages, T cells, and B cells, as well as FLS (Fukuda et al., 2014; Gui et al., 2014; Selvi et al., 2008). The presence of cannabinoid receptors in RA joints presents a possible target for novel anti-inflammatory and analgesic treatments.

One of the main mechanisms of cannabinoid modulation of inflammation is the regulation of cytokines. For example, THC attenuates the release of the pro-inflammatory cytokines IL-6 and TNF $\alpha$ in vitro from macrophages stimulated by the bacterial endotoxin lipopolysaccharide (Chang, Lee, \& Lin, 2001; Fischer-Stenger, Updegrove, \& Cabral, 1992). FLS cultured from RA synovial tissue and stimulated with the pro-inflammatory cytokines TNF $\alpha$ or IL-1 $\beta$, produce and release the pro-inflammatory cytokine IL-6. Pan cannabinoid agonists, such as WIN-55,212-2 and CP55940 (Lowin, Pongratz, \& Straub, 2016; Selvi et al., 2008), as well as the selective $\mathrm{CB}_{2}$ agonists, HU-308 and JWH133 (Fukuda et al., 2014; Gui et al., 2014), attenuate the secretion of IL-6 from stimulated FLS. Similarly, the endogenous cannabinoid, anandamide also attenuates TNF $\alpha$ stimulated FLS production of IL-6 and IL-8 (Lowin, Apitz, 
Anders, \& Straub, 2015). These data suggest that cannabinoids may reduce RA inflammation by attenuating the release of pro-inflammatory cytokines from FLS in the synovium.

Many exogenous cannabinoid agonists have undesirable behavioral and cognitive effects, including deficits in attention, memory, and motor function. Furthermore, chronic administration can lead to tolerance and abuse (Mechoulam \& Parker, 2013). One way to bypass the abuse potential and psychomimetic side effects of cannabinoid agonists is to target the endogenous cannabinoid (i.e., endocannabinoid) system. The two major endocannabinoids, Narachidonoylethanolamine (anandamide) and 2-arachidonoylglycerol (2-AG), are synthesized de novo from phospholipid precursors, and bind to and activate both cannabinoid receptors (Mechoulam \& Parker, 2013). Within the CNS, 2-AG is more abundant than anandamide, and acts as a full agonist at the $\mathrm{CB}_{1}$ and $\mathrm{CB}_{2}$ receptors (Ahn, McKinney, \& Cravatt, 2008). 2-AG is also present in the synovium of RA patients and throughout other areas of the body, including the spleen (i.e., lymphoid organ important in the immune system) (Hillard, 2000; Richardson et al., 2008). Monoacylglycerol lipase (MAGL) is the predominant catabolic enzyme for 2-AG, and metabolizes 2-AG into glycerol and arachidonic acid (Blankman, Simon, \& Cravatt, 2007). Pharmacological inhibition of MAGL, for example by the highly selective MAGL inhibitor JZL184, increases 2-AG systemically (Long et al., 2009). JZL184 attenuates acute inflammatory pain and edema induced by injecting the seaweed extract carrageenan (Ghosh et al., 2012). However, there are no published reports on the effects of MAGL inhibition in chronic inflammatory pain models, such as arthritis. 


\section{Cannabinoids in Inflammatory Arthritis}

Although cannabinoids are anti-inflammatory and analgesic with limited side effects compared to traditional immunosuppressants, research focused on the effects of cannabinoids in chronic inflammatory arthritis in vivo is limited. The oromucosal mouth spray Sativex, which contains a mixture of the Cannabis extracts THC and cannabidiol, decreases self-reports of RAinduced pain in humans (Blake, Robson, Ho, Jubb, \& McCabe, 2006). In the preclinical CIA model, repeated administration of cannabidiol, or its synthetic cannabinoid derivatives, decreases paw swelling and cartilage destruction (Haj et al., 2015; Malfait et al., 2000; Sumariwalla et al., 2004). Cannabidiol also attenuates the production of TNF- $\alpha$ from CIA synovial cells (Malfait et al., 2000). Similarly, CIA-induced inflammation, cartilage degradation, and bone erosion is also attenuated by the repeated administration of the selective $\mathrm{CB}_{2}$ agonists JWH133 and HU-308 (Fukuda et al., 2014; Gui, Liu, Liu, Su, \& Dai, 2015).

In addition to synthetic cannabinoid agonists, there is evidence that the endocannabinoid system modulates CIA. Just as MAGL catabolizes 2-AG, fatty acid amide hydrolase (FAAH) catabolizes the other endocannabinoid, anandamide. FAAH inhibition or genetic deletion increases tissue levels of anandamide. Genetic deletion of FAAH or repeated administration of the FAAH inhibitors URB597 or JNJ1661010 attenuates clinical signs of arthritis, and genetic deletion of FAAH attenuates joint damage in mice subjected to CIA (Kinsey et al., 2011b; Lowin et al., 2015). Interestingly, the FAAH inhibitor URB597 or genetic deletion of FAAH also reduces CIA-induced thermal hyperalgesia (i.e., hypersensitivity to noxious heat) (Kinsey et al., 2011b). These data from human and animal studies suggest that endocannabinoids attenuate inflammatory joint pain and overt signs of joint inflammation. 


\section{Combination Treatments}

In contrast to the classic approach of targeting a disease with a single drug, combined administration of multiple drugs offers several advantages. Combination therapies may maintain analgesic and anti-inflammatory efficacy by using lower doses of each drug, thereby decreasing the negative side effects (van Laar et al., 2012). In addition, chronic pain is often induced by multiple mechanisms. Although inflammation is the main perpetrator of RA pain, many patients also develop central sensitization, an increase in CNS pain pathway activity that causes hypersensitivity (Lee, 2013). Therefore, addressing multiple targets may increase the efficacy of the drug regimen.

The synthetic glucocorticoid receptor agonist dexamethasone (DEX) is used in preclinical research and reduces inflammation in the CIA model (Inglis et al., 2007a). A combination of DEX and the anti-inflammatory cytokine IL-4 attenuates CIA-induced paw inflammation (Kang et al., 2000; Kawalkowska et al., 2016). Interestingly, the combination of DEX and IL-4 also prevents the resurgence of CIA-induced paw swelling after treatment is terminated, indicating combination therapies may limit the need for long term use of glucocorticoids (GCs), thereby reducing undesirable side effects (Kawalkowska et al., 2016). Thus, there is evidence to support the idea that combining therapeutics with GCs may also reduce pain and inflammation in models of inflammatory arthritis with increased efficacy and decreased side effects. Endocannabinoid catabolic enzyme inhibition attenuates hyperalgesia and clinical signs of arthritis in the CIA model (Kinsey et al., 2011b), and the synthetic glucocorticoid receptor agonist DEX attenuates CIA-induced inflammation (Inglis et al., 2007a). The present study was designed to determine the analgesic and anti-inflammatory efficacy of (1) the MAGL inhibitor JZL184; (2) the glucocorticoid steroid dexamethasone (DEX); and (3) the 
combined administration of both JZL184 and DEX. Our overall goal was to ascertain whether pain and inflammation caused by inflammatory arthritis are further reduced by targeting both glucocorticoid and cannabinoid receptors than by targeting either receptor system alone.

\section{Methods}

\section{Animals}

Subjects were 226 male DBA/1J (Jackson Laboratory, Bar Harbor, ME) mice 9-12 weeks old at the start of the experiment. Males were chosen because multiple reports (Holmdahl, Jansson, \& Andersson, 1986; Jansson \& Holmdahl, 2001; Nilsson, Andren, Diaz de Stahl, \& Kleinau, 2009) indicate that female mice are protected from collagen induced arthritis and rarely develop arthritis. Mice were housed 3-5 per cage in a temperature $\left(20-22^{\circ} \mathrm{C}\right)$ and humidity controlled, AAALAC accredited facility, with ad libitum access to food and water, on a 12:12 light:dark cycle. The Institutional Animal Care and Use Committee at West Virginia University approved all the experimental protocols (14-1007).

\section{Collagen Induced Arthritis (CIA) Inflammatory Arthritis}

A timeline of the treatments is illustrated in Figure 2. Mice were anesthetized with isoflurane (Phoenix Pharmaceuticals, Burlingame, CA), and approximately $100 \mu 1$ of an emulsion of bovine type II collagen $(2 \mathrm{mg} / \mathrm{ml})$, dissolved in $0.05 \mathrm{M}$ acetic acid, in an equal volume of CFA was injected intradermally into the tail. Twenty-one days later (Brand et al., 2007; Impellizzeri et al., 2013), mice were given a secondary "booster" exposure to the collagen preparation, in an equal volume of incomplete Freund's adjuvant (IFA), slightly proximal from the first injection (Brand et al., 2007). Control mice were administered an emulsion of IFA and acetic acid, without collagen, at both exposures (Brand et al., 2007). The difference between 
CFA and IFA is that CFA contains heat-inactivated bacteria, to cause an innate immune response at the injection site. The CFA in the proposed experiment consisted of M. tuberculosis $(4 \mathrm{mg} / \mathrm{ml})$ (Becton, Dickinson and Company, Franklin Lakes, NJ) suspended into 85\% paraffin oil (Fisher Scientific, Pittsburgh, PA) and 15\% mannide monooleate (Fisher Scientific, Pittsburgh, PA) (Brand et al., 2007).

At the conclusion of the experiments, mice were humanely euthanized and hind limb tissue were collected, snap frozen in liquid nitrogen, and stored at $-80^{\circ} \mathrm{C}$ until assay.

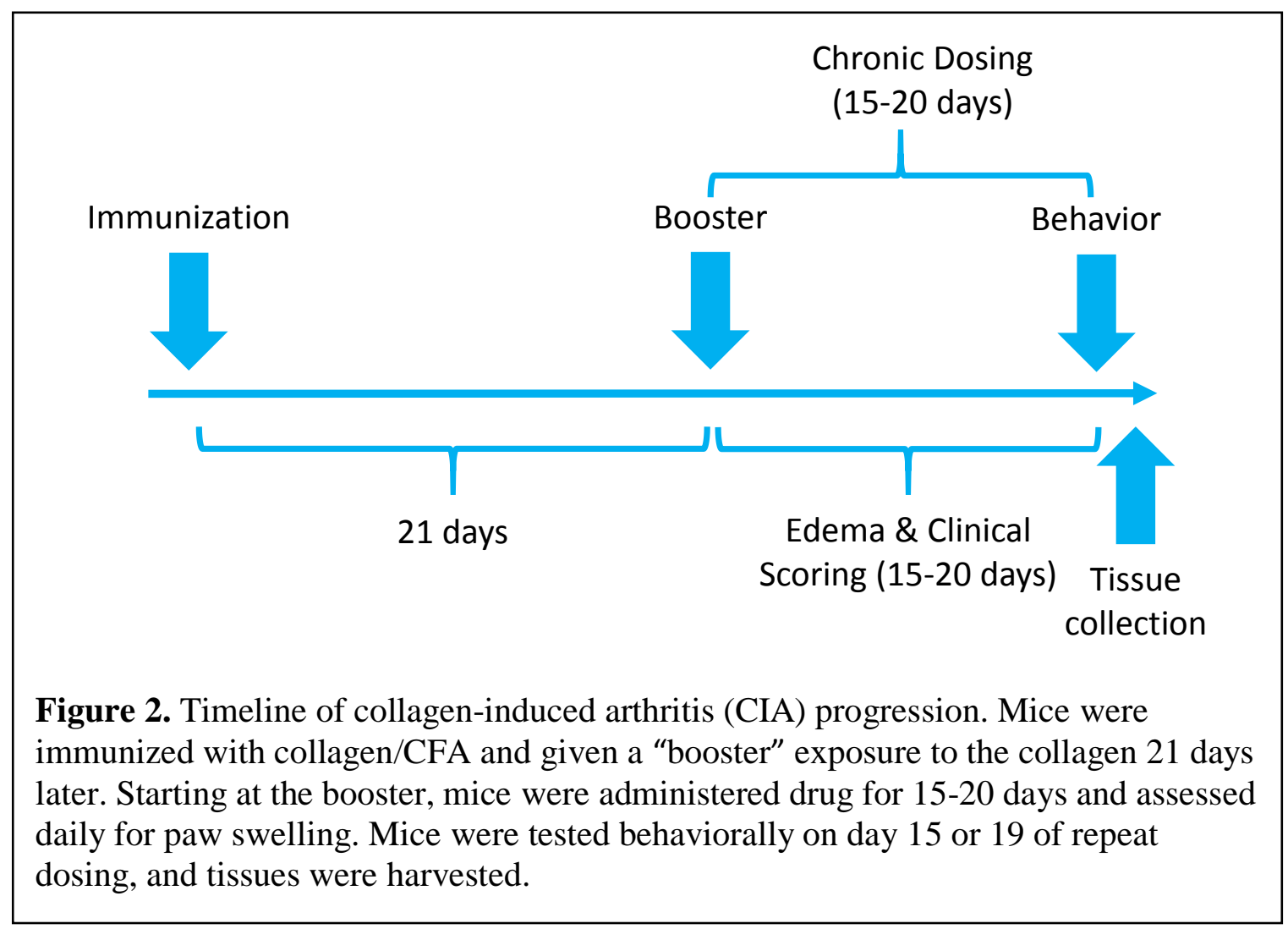

\section{Paw edema and clinical scoring}

After the "booster" injection, all four paws were examined daily for arthritic signs using a semi-quantitative clinical scoring system as follows: 0 , normal; 1 , erythema and mild swelling 
confined to the ankle joint or toes; 2 , erythema and mild swelling extending from the ankle to the midfoot or ankle joint; 3, erythema and moderate swelling extending from the ankle to the metacarpal/metatarsal joints; 4, erythema and severe swelling encompassing the ankle, foot, and digits (Kinsey et al., 2011b). The scores for each limb were summed for each mouse, resulting in a composite arthritis score with a maximum of 16 total points. Hind paw thickness was also measured with a digital micrometer, daily until the end of the experiment (Wixey WR100). Data from our lab as well as others indicate that CIA does not develop in our model until the "booster" collagen administration and daily handling before the booster reduces arthritis incidence (Brand et al., 2007).

\section{Behavioral Assessments}

Behavioral assessments of mechanical allodynia (i.e., pain perception to non-noxious touch) and thermal hyperalgesia were conducted on mice subjected to the CIA model of inflammatory arthritis. Mice were randomly assigned to each drug treatment at the start of each experiment and repeatedly dosed for 15-20 days (see Table 2). Repeated dosing and behavioral testing schedules were based on the established timeline for mice to develop signs of arthritis and preliminary data (see Figure 2 and results) (Brand et al., 2007; Gao et al., 2015). Given that the effects of MAGL inhibition on chronic inflammation are unknown, we used a prophylactic design, with the goal of increasing the likelihood of detecting an effect of the novel drug treatments. On behavioral testing days, mice were tested for allodynia followed by hyperalgesia. The experimenter was blinded to treatments throughout testing. Independent experimenter reliabilities for behavioral tests and caliper measurements were performed at multiple time points throughout the experiment and were correlated to $>0.98$. 
Mechanical allodynia. On test days, mice were brought into the testing room, weighed and injected. Immediately afterwards, mice were placed in ventilated polycarbonate chambers $(7.5 \times 9 \mathrm{~cm})$ on an aluminum mesh table where they were allowed to acclimate for at least 60 min before testing mechanical allodynia (Kinsey et al., 2009). Mechanical allodynia was tested by stimulating the plantar surface of each mouse hind paw with von Frey filaments (North Coast Medical, Morgan Hill, CA) using the "up-down" method (Chaplan, Bach, Pogrel, Chung, \& Yaksh, 1994; Crowe et al., 2015). Von Frey filaments are commonly used to test touch sensitivity in humans and other animals and are calibrated to bend at established weights. Each hind paw is stimulated approximately twice per second with each filament (0.16-6.0 g), starting with the $0.6 \mathrm{~g}$ filament. Hind paws were stimulated in ascending filament order until the mouse clutched or lifted its paw at least three out of five times. This was considered a positive response, and the sensitivity of each paw was tested by presenting the filaments in descending order to establish a sensory threshold.

Thermal Hyperalgesia. Mice were placed in ventilated polycarbonate chambers $(7.5 \times 9$ $\mathrm{cm}$ ) on a glass table and acclimated for at least $60 \mathrm{~min}$ before testing thermal hyperalgesia (Lichtman, Shelton, Advani, \& Cravatt, 2004). Thermal hyperalgesia was tested using the plantar stimulator apparatus (Hargreaves, Dubner, Brown, Flores, \& Joris, 1988; Lichtman et al., 2004). A plantar stimulator with a noxious heat source was positioned directly beneath the hind paws of each mouse, under a glass table. The latency for the mouse to withdraw its hind paw from the initiation of the radiant heat was scored as the dependent variable. A 20 s cutoff time was used to avoid the possibility of tissue damage (Kinsey et al., 2011a; Lichtman et al., 2004). 


\section{Cytokine and Myeloperoxidase (MPO) Enzyme-Linked Immunosorbent Assay (ELISA)}

Paw cytokine and MPO protein levels were quantified by sandwich ELISA, per manufacturer's protocol (R\&D Systems, Minneapolis, MN). Paw samples were separated at the ankle joint, cut into small pieces, and homogenized in $1.5 \mathrm{ml}$ phosphate-buffered saline using a Tissue Tearor (Bartlesville, OK). Proinflammatory (TNFa, IL-1 $\beta$, IL-6, IL-17) and antiinflammatory (IL-10) cytokines, and MPO were quantified in duplicate.

In brief, 96 well plates were coated with an anti-mouse capture antibody (derived from goat or rat immune cells that were exposed to the target mouse protein) and incubated at room temperature overnight. The following day, the samples and standards were added to each plate and incubated at room temperature for $2 \mathrm{~h}$. Samples were decanted and each plate was washed 3 times with wash buffer (0.05\% Tween 20 in phosphate buffered saline). A detection antibody was then added to each well and incubated at room temperature for $2 \mathrm{~h}$. The protein of interest (i.e., cytokine or MPO) became "sandwiched" between the capture antibody and detection antibody. Horseradish peroxidase (Streptavidin-HRP) was then added to each well and incubated for 20 min. HPR linked the detection antibody to a chemical tag (i.e., a 1:1 mixture of $\mathrm{H}_{2} \mathrm{O}_{2}$ and Tetramethylbenzidine) that produced color. The color reaction was halted after $20 \mathrm{~min}$ incubation in the dark by $2 \mathrm{~N} \mathrm{H}_{2} \mathrm{SO}_{4}$. Optical densities were determined with a $\mathrm{V}$ max kinetic microplate reader (Molecular Devices, Sunnyvale, CA) and read at $450 \mathrm{~nm}$ with a $560 \mathrm{~nm}$ correction. Values for known standards on each plate were plotted. The optical density of each unknown sample was fitted to this standard curve to determine the concentration of cytokine or MPO in each sample. Data are reported as the mean of the duplicates. No values were excluded for being above detection limit. The detection limit (protein $(\mathrm{min} / \mathrm{max})$ ) in $\mathrm{pg} / \mathrm{ml}$ for each assay 
were as follows: TNF $\alpha(2000 / 31.3)$, IL-1 $\beta$ (1000/15.6), IL-6 (1000/15.6), IL-17 (1000/15.6), IL$10(2000 / 31.3)$, and MPO (16000/250).

\section{Drugs}

The MAGL inhibitor JZL184 was purchased from Cayman Chemical (Ann Arbor, MI). The synthetic glucocorticoid DEX was purchased from Sigma-Aldrich (St Louis, MO). Both drugs were dissolved in a vehicle consisting of ethanol, Cremophor (Sigma-Aldrich, St Louis, MO), and saline in a ratio of 1:1:18 parts (Crowe et al., 2015; Kinsey \& Cole, 2013). All solutions were administered at room temperature at a volume of $10 \mu \mathrm{l} / \mathrm{g}$ body weight.

\section{Statistical Analyses}

Induction of CIA effect (as compared to non-CIA controls), was determined using unpaired t-tests with mechanical allodynia, thermal hyperalgesia, cytokine level, or MPO level as the dependent variable. All other data were analyzed using analysis of variance (ANOVA), followed by Tukey post hoc comparisons, with the exception of the DEX dose response data, for which Dunnett's post hoc comparison was used instead (all doses compared with CIA/VEH). For the first experiment, JZL184 data and DEX dose response data were analyzed using one way between subjects ANOVA with treatment (CIA/VEH, CIA/JZL184, CIA/DEX) as the independent variable and mechanical allodynia, thermal hyperalgesia, cytokine level, or MPO level as the dependent variable. In the second experiment, a one-way between subjects ANOVA of treatment condition (CIA/VEH, CIA/JZL184, CIA/DEX, CIA/JZL184+DEX) as the independent variable and mechanical allodynia, thermal hyperalgesia, cytokine level, or MPO level as the dependent variable was conducted, followed by Tukey post hoc comparisons. Data for clinical scores and edema were compared using mixed design ANOVA with days post immunization as the within subject variables and treatment as the between subjects variables. All 
data are presented as mean \pm S.E.M. Differences were considered statistically significant if $\mathrm{p}<$ 0.05 .

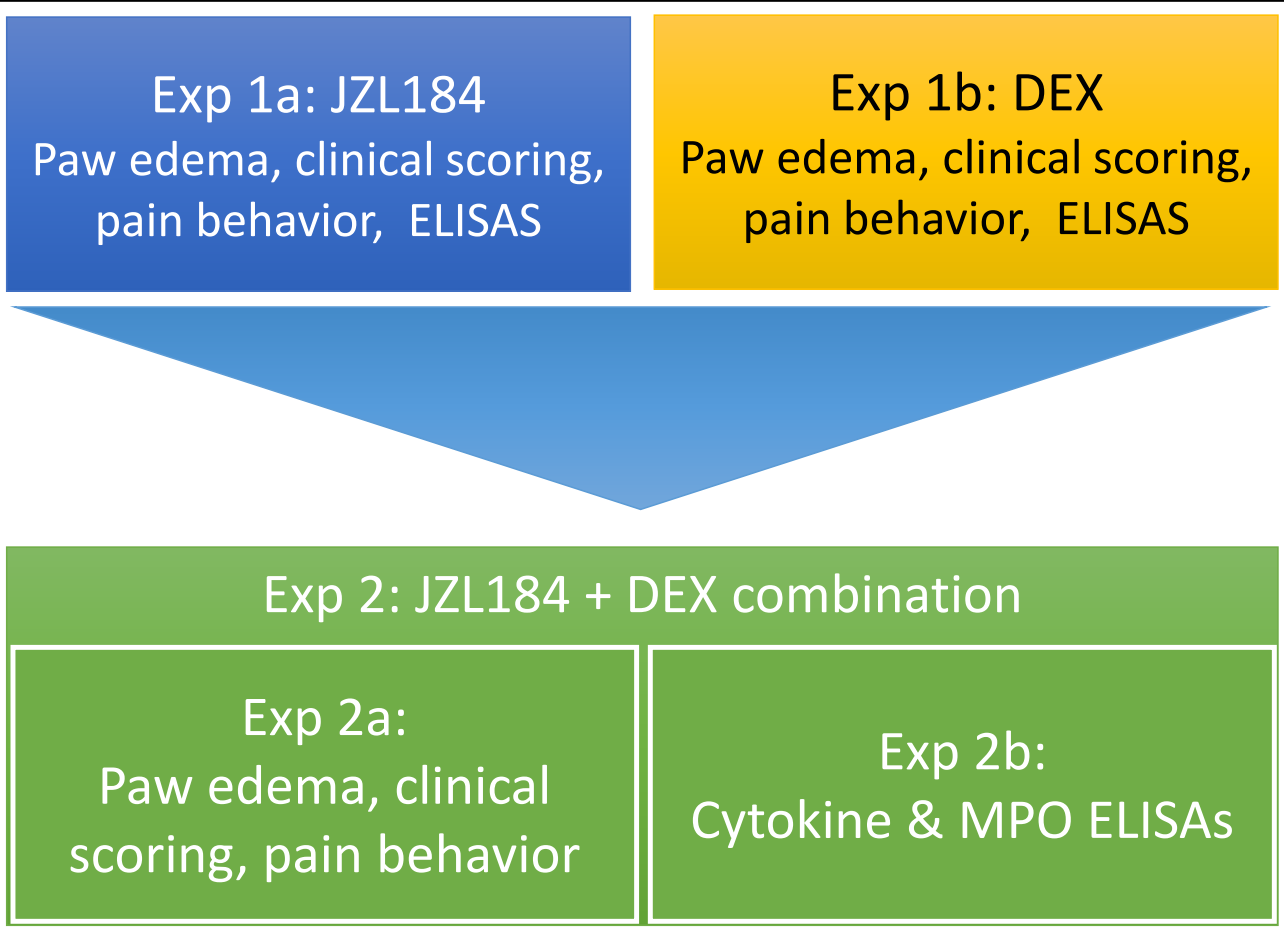

Figure 3. Diagram of experimental design. In the first experiment mice were subjected to CIA and the anti-arthritic efficacy of the MAGL inhibitor JZL184 and the glucocorticoid DEX was established. In the second experiment the analgesic and anti-inflammatory effects of the combination of JZL184 and DEX in the CIA model was elucidated. Mice were assessed for paw swelling, allodynia, and hyperalgesia. Then hind paws were dissected to analyze cytokine (TNF $\alpha$, IL-1 $\beta$, IL-6, IL-17, and IL-10) and MPO levels.

\section{Experimental Design}

An outline of the experimental design is summarized in Figure 3. Preliminary experiments were performed to determine the optimal behavioral testing days for mice subjected to CIA. Mice were administered a collagen/CFA emulsion to induce CIA, followed 21 days later by a booster exposure to collagen. Separate non-CIA control mice were also tested. Paw edema was assessed daily using digital calipers and arthritis severity was scored using a semiquantitative clinical scale. Mice were tested for mechanical allodynia and thermal hyperalgesia 
(Impellizzeri et al., 2013; Kinsey et al., 2009; Kinsey et al., 2011b) on days 22, 25, 28, 31, and 34 post immunization to determine the optimal behavioral testing timeline. Planned comparisons were used to establish appropriate testing days for the proceeding experiments, as choosing the optimal test day was the rationale for running these experiments.

The goal of the first experiment was to determine the appropriate doses of the MAGL inhibitor JZL184 (Exp1a) or the steroid DEX (Exp1b) to combine in the CIA model of inflammatory arthritis.

Exp1a. Determine anti-arthritic efficacy of the selective MAGL inhibitor JZL184. Mice were subjected to CIA or control procedures. Starting at the booster individual mice were administered a dose of JZL184 (8 mg/kg) (Kinsey et al., 2013; Schlosburg et al., 2010) or vehicle once daily, for 15 consecutive days (i.e., days 21-35; see Table 2). Separate nonCIA control mice were also tested. Paw edema was assessed daily using digital calipers and arthritis severity was scored using a semi-quantitative clinical scale. Mice were tested for mechanical allodynia and thermal hyperalgesia (Impellizzeri et al., 2013; Kinsey et al., 2009; Kinsey et al., 2011a) on day 14 of repeated dosing. On the $15^{\text {th }}$ day of repeated dosing, mice were humanly euthanized and hind limb tissues were collected. It was hypothesized that JZL184 (8 mg/kg) would attenuate CIA-induced paw swelling and behavioral pain responses.

A separate group of mice were subjected to CIA and administered a dose of JZL184 (4 mg/kg) (Kinsey et al., 2013; Schlosburg et al., 2010) or vehicle once daily, for 15 consecutive days. Disease progression was assessed via paw swelling, clinical scoring, allodynia, and hyperalgesia (see Table 2 ). On the $15^{\text {th }}$ day of repeated dosing, mice were 
humanly euthanized and hind limb tissues were collected. Due to a lack of allodynic or hyperalgesic effect of CIA, mice were dosed consecutively for an additional three days and tested for grip strength (see Appendix A) on day 16 and humanly euthanized and hind limb tissue were collected on day 18. It was hypothesized that JZL184 (4 mg/kg) would be subeffective at attenuating CIA-induced paw swelling and behavioral pain responses.

Exp1b. Determine anti-arthritic efficacy of the synthetic glucocorticoid steroid dexamethasone. As in Exp1a, CIA was induced and a dose response curve was constructed to establish the anti-inflammatory and analgesic potency of the synthetic steroid dexamethasone (DEX; 0.0625, 0.125, 0.25, or 0.5 mg/kg) (Inglis et al., 2007a). For 15 consecutive days, mice were administered a dose of DEX or vehicle and then assessed for paw swelling, disease progression (i.e., clinical scoring), allodynia, and hyperalgesia (see Table 2). Due to the powerful anti-inflammatory effects of DEX, a second cohort of mice was run to test even lower doses of dexamethasone (i.e., 0.015625, 0.03125 , or $0.5 \mathrm{mg} / \mathrm{kg}$ ) than originally proposed. For 15 consecutive days, mice were administered a dose of DEX or vehicle and then assessed for paw swelling, disease progression, allodynia, and hyperalgesia (see Table 2). Due to a lack of a behavioral effect of CIA, mice were dosed consecutively for an additional five days and retested on day 19, and humanly euthanized, and hind limb tissue were collected on day 21 . It was hypothesized that DEX would dose dependently attenuate CIA-induced paw swelling and pain responses. 
The goal of the second experiment was to determine the analgesic and anti-inflammatory effects of repeated combined administration of both the MAGL inhibitor JZL184 and the synthetic glucocorticoid DEX in the CIA model of inflammatory arthritis.

\section{Exp2a. Determine the behavioral and arthritic effects of dual administration of} $\underline{\text { subeffective doses of both JZL184 and dexamethasone. Mice were administered JZL184 }}$ (4 mg/kg), DEX (0.015625 mg/kg), JZL184 (4 mg/kg) +DEX (0.015625 mg/kg), or vehicle once daily, for 15 consecutive days following the booster exposure to collagen (i.e., day 21) (see Table 2). During repeated drug administration, mice were assessed daily for gross signs of paw inflammation and disease progression was assessed by clinical scoring. After 15 days of treatment (i.e., day 35), each mouse was tested for allodynia, and hyperalgesia, as detailed above. Again, due to a null CIA effect in the behavioral tests, mice were consecutively dosed for another four days and retested on day 19, humanly euthanized, and hind limb tissues were collected. It was hypothesized that the combination of subeffective doses of JZL184 and DEX would attenuate CIA-induced paw swelling and pain responses to a greater degree than either drug alone. 
Experiment 1a: JZL184 Dosing

\begin{tabular}{|c|c|c|c|c|c|c|c|}
\hline Condition & Control & CIA & CIA & Condition & Control & CIA & CIA \\
\hline $\begin{array}{c}\text { JZL184 } \\
(\mathrm{mg} / \mathrm{kg})\end{array}$ & 0 & 0 & 8 & $\begin{array}{c}\text { JZL184 } \\
(\mathrm{mg} / \mathrm{kg})\end{array}$ & 0 & 0 & 4 \\
\hline Mice & 12 & 12 & 12 & Mice & 10 & 10 & 10 \\
\hline
\end{tabular}

Experiment 1b: DEX DRC

\begin{tabular}{|c|c|c|c|c|c|c|}
\hline $\begin{array}{c}\text { Condition } \\
\begin{array}{c}\text { DEX } \\
\text { (mg/kg) }\end{array}\end{array}$ & 0 & 0 & 0.0625 & 0.125 & 0.25 & 0.5 \\
\hline $\begin{array}{c}\text { Mice } \\
\text { Condition }\end{array}$ & 10 & 10 & 9 & 10 & 9 & 10 \\
\hline $\begin{array}{c}\text { DEX } \\
\text { (mg/kg) }\end{array}$ & 0 & 0 & 0.015625 & 0.03125 & 0.5 & \\
\begin{tabular}{c} 
Mice \\
\hline
\end{tabular} & 10 & 10 & 9 & 9 & 9 & \\
\hline
\end{tabular}

Experiment 2: Combination JZL + DEX

\begin{tabular}{|c|c|c|c|}
\hline & Control & \multicolumn{3}{|c|}{ CIA } \\
\hline Vehicle & 9 & 11 & 8 \\
\hline DEX & - & 9 & 9 \\
\hline
\end{tabular}

Table 2. Treatment groups and total sample size for each experiment.

Exp2b. Determine the inflammatory effects of dual JZL184/DEX administration. Hind paws were dissected and homogenized to analyze proinflammatory (TNF $\alpha$, IL-1 $\beta$, IL-6, and IL-17) and anti-inflammatory (IL-10) cytokine and myeloperoxidase (MPO) levels using sandwich ELISA. It was hypothesized that the combination of JZL184 and DEX would decrease proinflammatory cytokine levels and increase anti-inflammatory cytokine levels. 


\section{Results}

\section{Preliminary data: CIA induces paw swelling and thermal hyperalgesia}

Due to the inconsistencies with the CIA model in our lab in the past, we first ran a pilot group of mice to demonstrate that we could induce CIA and to establish a behavioral timeline. Mice were immunized with collagen to induce CIA, and given a booster exposure to collagen 21 days later. A group of non-CIA control mice were given control emulsions. CIA induced an increase in arthritic clinical scores $[F(1,15)=21.547 ; \mathrm{p}<.01$; Figure 4A $]$ and paw thickness $[F$ $(1,15)=7.693 ; p<.01 ;$ Figure 4B] compared to non-CIA controls.

Mice were tested for mechanical allodynia and thermal hyperalgesia on days $22,25,28$, 31, and 34 post immunization. In the von Frey test, there was no interaction between treatment and days post immunization $[F(4,22)=.6786, \mathrm{p}=.1347$; Figure $4 \mathrm{C}]$, nor was there a main effect of treatment $[F(1,22)=.8031, \mathrm{p}=.8031]$ or days post immunization $[F(4,22)=.579, \mathrm{p}=$ .6786], indicating CIA did not induce mechanical allodynia. Although in the plantar stimulator test there was also no interaction between treatment and days post immunization $[F(4,22)=$ $1.828, \mathrm{p}=.1305$; Figure 4D] or main effect of days post immunization $[F(4,22)=2.173, \mathrm{p}=$ $.0786]$, there was a main effect of treatment $[F(1,22)=15.612, \mathrm{p}<.01]$, indicating CIA induced thermal hyperalgesia. Although there was only a main effect of collagen treatment and not an interaction effect in the plantar stimulator test, data for each individual testing day were analyzed based on a planned comparison to establish a behavioral timeline. Post hoc analyses revealed that CIA induced hyperalgesia on days 22, 31, and 34, but not days 25 or 28 post immunization. Based on these data behavioral testing was performed at least 31 days post immunization in all proceeding experiments. Although CIA did not induce mechanical allodynia in the preliminary 
experiment, mechanical allodynia was still tested in experiments one and two, because it previously has been the most consistent behavioral test for the CIA model in our lab.

\section{Experiment 1a: Repeated MAGL inhibitor JZL184 partially attenuates CIA-induced paw cytokine level increase}

We next performed repeated administration of the MAGL inhibitor JZL184 (8 or 4 $\mathrm{mg} / \mathrm{kg}$ ) to establish a subthreshold dose to be combined with the steroid DEX in experiment two. Tolerance develops after repeated dosing (6 days) of JZL184 (16 or 40 mg/kg) (Kinsey et al., 2013; Schlosburg et al., 2010). Therefore, we hypothesized that a lower dose of JZL184 (4 $\mathrm{mg} / \mathrm{kg}$ ) would be ineffective at attenuating CIA-induced pain and inflammation without causing tolerance after repeated administration.

We first ran mice with only a moderate dose of JZL184 $(8 \mathrm{mg} / \mathrm{kg})$ to establish an effective dose of JZL184. Acute administration of JZL184 (8 mg/kg) attenuates CIA-induced thermal hyperalgesia (Nass, 2015), but these data were obtained before the model was optimized. Mice were administered the MAGL inhibitor JZL184 (8 mg/kg, s.c.) or vehicle once daily for 15 consecutive days starting at the booster. There was an interaction in paw swelling between treatment and days post immunization as measured by arthritic clinical scores $[F(30,33)=$ 10.544; $\mathrm{p}<.01 ;$ Figure 5A $]$ and paw thickness $[F(30,33)=7.693 ; \mathrm{p}<.01 ;$ Figure 5B $]$. Post hoc comparisons revealed that CIA increased arthritic scores and paw thickness. Furthermore, post hoc analyses also indicated a statistical increase in paw swelling in JZL184/CIA mice compared to CIA. However, based on data from other cohorts of mice the effect is probably due to differences in paw swelling across collagen exposed mice and unlikely to replicate. Thus, the JZL184 effect is probably not biologically relevant. 
Mice were tested for mechanical allodynia and thermal hyperalgesia on day 14 post booster. There was a significant effect of drug treatment on mechanical allodynia $[F(2,33)=$ 4.653, $\mathrm{p}<.05$; Figure 5C], although post hoc analyses indicated CIA did not induce mechanical allodynia. CIA induced thermal hyperalgesia $[F(2,33)=11.623, \mathrm{p}<.01$; Figure 5D], but JZL184 (8 mg/kg) did not reverse this CIA-induced thermal hyperalgesia.

Mice were humanely euthanized day 15 post booster and hind limb tissue were harvested. Right hind paws were separated and homogenized. A sandwich ELISA was used to analyze proinflammatory (TNF $\alpha$, IL-1 $\beta$, IL-6, and IL-17) and anti-inflammatory (IL-10) cytokine and MPO levels. CIA significantly increased paw levels of the proinflammatory cytokines TNF $\alpha[F$ $(2,33)=7.298, \mathrm{p}<.01 ;$ Figure 6A $],$ IL-1 $\beta[F(2,33)=7.149, \mathrm{p}<.01 ;$ Figure 6B $]$, IL-6 $[F(2,33)$ $=9.188, \mathrm{p}<.01$; Figure 6C $]$, and IL-17 $[F(2,33)=7.069, \mathrm{p}<.01$; Figure 6D $]$, the antiinflammatory cytokine IL-10 $[F(2,33)=8.978, \mathrm{p}<.01$; Figure 6E $]$, and the neutrophil marker MPO $[F(2,33)=16.859, \mathrm{p}<.01$; Figure 6F $]$. Post hoc analyses revealed that the JZL184/CIA mice did not significantly differ in proinflammatory (TNF $\alpha$, IL-1 $\beta$, IL-6, and IL-17) and antiinflammatory (IL-10) cytokine from either the CIA or control mice. These results suggest that JZL184 (8 mg/kg) partially attenuates cytokine levels in CIA paws. MPO levels were not affected by JZL184 (8 mg/kg).

Due to the partial attenuation of CIA paw inflammation by JZL184 (8 mg/kg), we next tested a separate group of mice with a low dose of JZL184 (4 mg/kg) to establish a subeffective dose. For 18 consecutive days, mice were administered the MAGL inhibitor JZL184 (4 mg/kg, s.c.) or vehicle once daily. There was an interaction between treatment and days post immunization in clinical scores $[F(34,27)=5.854$; $p<.01$; Figure 7A $]$ and caliper 
measurements $[F(34,27)=6.310 ; \mathrm{p}<.01 ;$ Figure 7B $]$. Post hoc comparisons revealed that CIA increased paw swelling, but JZL184 (4 mg/kg) was ineffective.

On day 15 post booster, mice were tested for pain-related behaviors. CIA did not induce mechanical allodynia $[F(2,27)=1.701 ; \mathrm{p}=.2015$; Figure 7C $]$ or thermal hyperalgesia $[F(2,27)$ $=1.722 ; \mathrm{p}=.4340 ;$ Figure 7D]. Due to the lack of CIA effect, there was no JZL184 (4 mg/kg) attenuation of pain-related behaviors.

On day 18 post booster mice were humanely euthanized and hind limbs were harvested. Similar to the previous experiment, CIA significantly increased paw levels of cytokines TNF $\alpha[F$ $(2,27)=7.298, \mathrm{p}<.01$; Figure 8A $],$ IL-1 $\beta[F(2,27)=5.662, \mathrm{p}<.01 ;$ Figure 8B $]$, IL-6 $[F(2,27)$ $=7.378, \mathrm{p}<.01$; Figure 8C $]$, IL-17 $[F(2,27)=12.035, \mathrm{p}<.01$; Figure 8D $]$, IL-10 $[F(2,27)=$ 7.547, p <.01; Figure 8E]. However, CIA did not significantly increase MPO $[F(2,27)=3.294$, p =0525; Figure 8F] levels. Post hoc analyses revealed that JZL184 (4 mg/kg) had no effect on pro and anti-inflammatory (IL-10) cytokine levels or MPO.

These data reveal that JZL184 (4 mg/kg) is subeffective in CIA-induced paw swelling and inflammatory mediators.

\section{Experiment 1b: Repeated steroid dexamethasone attenuates CIA-induced pain and inflammation}

We next performed a dose response curve of repeated administration of the steroid DEX to establish a subthreshold dose to be combined with JZL184 in experiment two. Repeated (15 days) DEX (0.5 mg/kg) administration attenuates CIA-induced paw swelling, allodynia, and hyperalgesia (Unpublished data from our lab). Therefore, we hypothesized that repeated administration of a lower dose of $\operatorname{DEX}(0.25 \mathrm{mg} / \mathrm{kg}$ or below $)$ would yield a subthreshold dose 
that does not attenuate arthritic signs. CIA induced paw swelling as measured by clinical scores $[F(15,18)=5.259 ; \mathrm{p}<.01 ;$ Figure 9A $]$ and paw thickness $[F(15,18)=4.527 ; \mathrm{p}<.01$; Figure 9B] compared to non-CIA controls. Mice were administered the steroid DEX $(0.0625,0.125$, 0.25 , or $0.5 \mathrm{mg} / \mathrm{kg} ;$ s.c.) or vehicle once daily for 15 consecutive days. In CIA mice there was an interaction between drug treatment and days post immunization in clinical scores $[F(4,60)=$ 4.902; $\mathrm{p}<.01$; Figure 9A $]$ and paw thickness $[F(4,60)=4.388 ; \mathrm{p}<.01$; Figure 9B $]$. Post hoc comparisons revealed that all doses of DEX attenuated CIA-induced increase in arthritic scores and paw diameter.

Mice were tested for allodynia and hyperalgesia on day 15 post booster. CIA had no effect on mechanical allodynia, compared to control mice $[t(18)=1.828, \mathrm{p}=.0842$; Figure 9C]. However, DEX $(0.0625,0.125$, or $0.5 \mathrm{mg} / \mathrm{kg})$ decreased paw withdrawal thresholds in the von Frey test $[F(4,43)=4.537 ; \mathrm{p}<.01 ;$ Figure 9C $]$, indicating an anti-allodynic effect. Similarly, CIA per se did not induce thermal hyperalgesia in the plantar stimulator test $[t(18)=1.144, \mathrm{p}=$ .2674; Figure 9D]. DEX had no effect on thermal hyperalgesia as compared with CIA mice [ $F$ $(4,43)=.184 ; p=.9456 ;$ Figure 9D]. Due to the robust reduction in paw swelling by DEX (all doses), ELISAs were not run to determine cytokine and MPO levels in these mice.

Because DEX $(\geq 0.0625 \mathrm{mg} / \mathrm{kg})$ attenuated CIA-induced paw swelling, we ran a second dose response curve with lower doses of $\operatorname{DEX}($ i.e., 0.015625 or $0.03125 \mathrm{mg} / \mathrm{kg}$ ) to find a subthreshold dose. The highest dose (i.e., $0.5 \mathrm{mg} / \mathrm{kg}$ ) and negative controls were also included. CIA increased arthritic clinical scores $[F(14,18)=11.310 ; \mathrm{p}<.01$; Figure 10A $]$ and paw thickness $[F(14,18)=6.493 ; \mathrm{p}<.01 ;$ Figure 10B $]$ compared to non-CIA controls. For 20 consecutive days mice were administered DEX or vehicle once daily. There was a significant interaction between DEX treatment and days post immunization in mice administered collagen in 
clinical scores $[F(42,32)=6.493 ; \mathrm{p}<.01 ;$ Figure 10A $]$ and paw thickness $[F(42,32)=5.470 ; \mathrm{p}$ $<.01$; Figure 10B]. Post hoc analyses revealed all doses of DEX $(\geq 0.015625 \mathrm{mg} / \mathrm{kg})$ attenuated CIA-induced hind paw thickness, but clinical scores were reduced at $(\geq 0.03125 \mathrm{mg} / \mathrm{kg} \mathrm{DEX})$.

On day 19 post booster, CIA increased mechanical allodynia $[t(18)=5.916, \mathrm{p}<.01$;

Figure 10C $]$ and thermal hyperalgesia $[t(18)=4.829, \mathrm{p}<.01$; Figure 10D], as compared to nonCIA control mice. Interestingly, in CIA mice, only the high dose DEX $(0.5 \mathrm{mg} / \mathrm{kg})$ attenuated mechanical allodynia $[F(3,33)=4.919 ; \mathrm{p}<.01 ;$ Figure 10C $]$ and thermal hyperalgesia $[F(3,32)$ $=3.559, \mathrm{p}<.05 ;$ Figure 8D].

Mice were humanely euthanized on day 20 post booster and proinflammatory (TNF $\alpha$, IL$1 \beta$, IL-6, and IL-17) and anti-inflammatory (IL-10) cytokine and MPO paw levels were analyzed by sandwich ELISA. CIA significantly increased paw levels of IL-1 $\beta[t(18)=-2.791, \mathrm{p}<.05$;

Figure 11B], IL-6 $[t(18)=-3.043, \mathrm{p}<.01$; Figure 11C $]$, and IL-10 $[t(18)=-2.605, \mathrm{p}<.05$; Figure 11E] as compared to non-CIA controls. The CIA increase in IL- $1 \beta[F(3,32)=5.317, \mathrm{p}$ $<.01$; Figure 11B $]$, IL-6 $[F(3,32)=6.900, \mathrm{p}<.01$; Figure 11C $]$, and $\mathrm{IL}-10[F(3,32)=4.573, \mathrm{p}$ $<.01$; Figure 11E] tissue levels was attenuated by all doses of DEX $(\geq 0.015625 \mathrm{mg} / \mathrm{kg})$. Similarly, the paw levels of TNF $\alpha[t(18)=-2.703, \mathrm{p}<.05$; Figure 11A $]$, IL-17 $[t(18)=-2.112, \mathrm{p}$ $<.05$; Figure 11D], and MPO $[t(18)=-4.363, \mathrm{p}<.01$; Figure 11F $]$ were increased in CIA mice compared to non-CIA controls. However, only DEX $(\geq 0.03125 \mathrm{mg} / \mathrm{kg})$ attenuated the CIA increase in paw $\operatorname{TNF} \alpha[F(3,32)=4.552, \mathrm{p}<.01$; Figure 11A $]$, IL-17 $[F(3,32)=3.724, \mathrm{p}<.05$; Figure 11D], and MPO $[F(3,32)=6.941, \mathrm{p}<.01$; Figure 11F $]$.

These data indicate that DEX $(0.015625 \mathrm{mg} / \mathrm{kg})$ was ineffective at attenuating CIAinduced arthritic clinical scores, pain-related behavior, and proinflammatory cytokines TNF $\alpha$ and IL-17 and MPO paw levels. Therefore, DEX (0.015625 mg/kg) was used in Experiment Two. 


\section{Experiment 2a: Repeated dual administration of the MAGL inhibitor JZL184 and the steroid dexamethasone attenuates CIA-induced paw swelling}

In Experiment Two, we determined the effects of dual administration of subeffective doses of the MAGL inhibitor JZL184 (4 mg/kg) and the steroid DEX (0.015625 mg/kg), as established in Experiment One. We hypothesized that combined JZL184 and DEX would attenuate CIA-induced arthritic signs, but would be ineffective alone. CIA increased arthritic

clinical scores $[F(19,18)=11.098 ; \mathrm{p}<.01 ;$ Figure 12A $]$ and paw thickness $[F(19,18)=6.348 ; \mathrm{p}$ $<.01$; Figure 12B] compared to non-CIA controls. Mice were administered the MAGL inhibitor JZL184 (4 mg/kg), the steroid DEX (0.015625 mg/kg), a combination of JZL184 (4 mg/kg) and DEX $(0.015625 \mathrm{mg} / \mathrm{kg})$, or vehicle subcutaneously once daily for 19 consecutive days. In CIA mice, there was a significant interaction between treatment and days post immunization in clinical scores $[F(60,43)=4.902 ; \mathrm{p}<.01 ;$ Figure 12A $]$ and paw thickness $[F(60,43)=4.388 ; \mathrm{p}$ $<.01$; Figure 12B]. Post hoc comparisons revealed that DEX and coadministration of JZL184/DEX attenuated CIA-induced arthritic clinical scores and paw thickness.

Mice were tested for mechanical allodynia and thermal hyperalgesia on day 19 post booster. CIA-induced mechanical allodynia $[t(18)=2.210, \mathrm{p}<.05$; Figure 12C $]$ compared to non-CIA control mice. However, in mice administered collagen JZL184, DEX, or JZL/DEX did not attenuate the CIA-induced increase in paw withdrawal thresholds in the von Frey test $[F(3$, $33)=1.729 ; p=.1801 ;$ Figure 12C $]$. CIA did not induce thermal hyperalgesia $[t(18)=1.660, p$ $=.1142$; Figure 12D]. Due to the lack of a CIA effect, post hoc comparisons revealed no significant attenuation of hyperalgesia by JZL184, DEX, or JZL/DEX $[F(3,33)=1.611$, p $=.2056$; Figure 12D]. Taken together, these results suggest that JZL/DEX attenuates CIAinduced paw swelling, but the effect is probably driven by DEX. 


\section{Experiment 2b: Repeated dual administration of the MAGL inhibitor JZL184 and the steroid dexamethasone did not attenuate CIA-induced increase in paw cytokines and MPO}

Mice were humanely euthanized on day 19 post booster and hind limbs were taken. Proinflammatory (TNF $\alpha$, IL-1 $\beta$, IL-6, and IL-17) and anti-inflammatory (IL-10) cytokine and MPO levels were analyzed by sandwich ELISA. CIA significantly increased paw levels of the proinflammatory cytokines $\mathrm{TNF} \alpha[t(18)=-2.521, \mathrm{p}<.05$; Figure 13A $], \mathrm{IL}-1 \beta[t(18)=-2.635, \mathrm{p}$ $<.05$; Figure 13B], IL-6 [t(18) = -32.535, $\mathrm{p}<.05$; Figure 13C], IL-17 $[t(18)=-2.416, \mathrm{p}<.05$;

Figure 13D], and the neutrophil marker MPO $[t(18)=-4.036, \mathrm{p}<.01$; Figure 13F $]$ as compared to non-CIA controls. CIA paw tissue increase in $\operatorname{TNF} \alpha[F(3,33)=1.058, \mathrm{p}=.3801$; Figure 13A $], \operatorname{IL}-1 \beta[F(3,33)=.569, p=.6392$; Figure 13B $]$, IL-6 $[F(3,33)=.856, p=.4733$; Figure 13C $]$ IL-17 $[F(3,33)=.985, \mathrm{p}=.4118$; Figure 13D $]$, and $\operatorname{MPO}[F(3,33)=1.100, \mathrm{p}=.3632$; Figure 13F] was unaffected by JZL184 (4 mg/kg), DEX (0.015625 mg/kg), or JZL184 (4 $\mathrm{mg} / \mathrm{kg})+\operatorname{DEX}(0.015625 \mathrm{mg} / \mathrm{kg})$. Similarly, CIA did not increase paw tissue levels of IL-10 $[t(18)=-1.475, \mathrm{p}=.1575 ;$ Figure 13E $]$ and JZL184, DEX, or JZL/DEX had no effect on IL-10 $[F(3,33)=1.1274, \mathrm{p}=.2995 ;$ Figure 13E $]$

Taken together, these data indicate that dual administration of JZL184/DEX did not affect the CIA-induced increase in proinflammatory cytokines or MPO paw tissue levels.

\section{Discussion}

The overall goal of the present study was to elucidate the effects of targeting cannabinoid and glucocorticoid receptors alone and in combination, to attenuate pain and inflammation caused by the collagen-induced arthritis (CIA) mouse model of inflammatory arthritis. This is the first study to investigate monoacylglycerol lipase (MAGL) inhibition in a chronic pain model, either alone or in combination with the synthetic steroid dexamethasone (DEX). 
The first aim (Exp 1a) of the present study was to determine the efficacy of the selective MAGL inhibitor JZL184 in attenuating inflammatory arthritis. Repeated administration of JZL184 (4 or 8 mg/kg, s.c.) did not attenuate CIA-induced paw swelling. However, JZL184 (8 $\mathrm{mg} / \mathrm{kg}$ ) partially attenuated the CIA-increased proinflammatory (IL-1 $\beta$, TNF $\alpha$, IL-6, \& IL-17) and anti-inflammatory (IL-10) cytokines. These data align with previous studies demonstrating that MAGL inhibition by JZL184 attenuates proinflammatory (IL-1 $\beta$, TNF $\alpha, \&$ IL-6) and antiinflammatory (IL-10) cytokines in other preclinical models of inflammation (Kerr et al., 2013; Kinsey et al., 2011c).

The second Aim (Exp 1b) of the present study was to determine the efficacy of the synthetic glucocorticoid receptor agonist dexamethasone on CIA-induced inflammation and pain. Repeated administration of DEX ( $\geq 0.03125 \mathrm{mg} / \mathrm{kg}$, s.c. $)$ attenuated CIA-induced arthritic clinical scores. DEX ( $\geq 0.015625 \mathrm{mg} / \mathrm{kg}$, s.c. $)$ attenuated the CIA-increased proinflammatory (IL-1 $\beta$ \& IL-6) and anti-inflammatory (IL-10) cytokines, whereas DEX ( $\geq 0.03125 \mathrm{mg} / \mathrm{kg}$, s.c. $)$ attenuated the CIA-increased proinflammatory (TNF $\alpha$ and IL-17) cytokines and MPO. These results confirm previous reports that DEX attenuates CIA-induced paw swelling and cytokine levels (Inglis et al., 2007a; Kawalkowska et al., 2016; Pu et al., 2016). This is the first report to show that $\operatorname{DEX}(0.5 \mathrm{mg} / \mathrm{kg}$, s.c. $)$ also attenuates CIA-induced allodynia and hyperalgesia.

The third Aim $(\operatorname{Exp} 2)$ of the present study was to determine the behavioral and immune effects of dual administration of subeffective doses of both JZL184 and dexamethasone. Due to its absence of anti-inflammatory effects in overt paw swelling and paw cytokine levels, the 4 $\mathrm{mg} / \mathrm{kg}$ dose of JZL184, was chosen. Similarly, the $0.015625 \mathrm{mg} / \mathrm{kg}$ dose of DEX was chosen, due to its lack of attenuation of CIA-induced arthritic clinical scores and paw cytokine (IL-1 $\beta$, IL-6, \& IL-10) levels. Repeated dual administration of JZL184 (4 mg/kg) and DEX (0.015625 
$\mathrm{mg} / \mathrm{kg})$ attenuated CIA-induced paw swelling. However, solo DEX $(0.015625 \mathrm{mg} / \mathrm{kg})$ also reduced paw swelling to a similar extent as JZL184/DEX, indicating that this effect is probably driven by DEX. JZL184/DEX did not attenuate the CIA-induced increase in pro-inflammatory cytokine and MPO paw levels.

There is a paucity of research on behavior using the CIA model of inflammatory arthritis. Hence, we first performed a behavioral time course and determined that in our lab, CIA-induced thermal hyperalgesia starting 31 days post immunization, which corresponds to the beginning of a significant increase in paw swelling in CIA mice. These results align with previous reports that the onset of CIA-induced thermal hyperalgesia coincides with a significant increase in paw swelling in rats (Nieto, Clark, Grist, Chapman, \& Malcangio, 2015). It was surprising that repeated administration of JZL184 $(8 \mathrm{mg} / \mathrm{kg})$ did not attenuate CIA-induced thermal hyperalgesia, because MAGL inhibition attenuates acute inflammatory pain induced by intraplantar injection of carrageenan (Ghosh et al., 2012; Ignatowska-Jankowska et al., 2013), a seaweed extract known to cause paw swelling. One possible explanation for the weak MAGL effect is that the inflammatory response in our model is more robust than other models. In support of this idea, JZL184 $(8 \mathrm{mg} / \mathrm{kg})$ did not reduce overt paw swelling despite partially attenuating paw cytokine levels. Alternatively, the mice may have developed partial tolerance to repeated JZL184 administration. Repeated administration of high doses (e.g., $40 \mathrm{mg} / \mathrm{kg}$ or 16 $\mathrm{mg} / \mathrm{kg}$ ) of JZL184 reduces $\mathrm{CB}_{1}$ expression and sensitization (Schlosburg et al., 2010). Furthermore, tolerance develops to the analgesic and gastroprotective effects of JZL184 after repeated administration ( 6 days) of high doses ( $40 \mathrm{mg} / \mathrm{kg}$ or $16 \mathrm{mg} / \mathrm{kg}$ ), but not low dose (4 $\mathrm{mg} / \mathrm{kg}$ ) in mice (Kinsey et al., 2013; Schlosburg et al., 2010). Although the lower dose of JZL184 (8 mg/kg) used in the present study did not show tolerance at the cytokine level after 15 
days of repeated dosing, the effects of a 15 day treatment of JZL184 on cannabinoid receptor expression and sensitization are unknown and may reflect differences in $\mathrm{CB}_{1}$ vs. $\mathrm{CB}_{2}$ susceptibility to tolerance.

Tolerance to JZL184 may be prevented at low doses (Kinsey et al., 2013). Therefore, we ran a separate cohort of mice to investigate the effects of JZL184 (4 mg/kg) on CIA-induced pain and inflammation. JZL184 (4 mg/kg) did not attenuate CIA-induced paw swelling or paw cytokine levels, indicating that $4 \mathrm{mg} / \mathrm{kg}$ is a subeffective dose in the CIA model. That said, there was no CIA effect in either the von Frey or plantar stimulator tests to use as a comparison group to properly determine the potential anti-analgesic effects of JZL184 (4 mg/kg). Although the von Frey and plantar stimulator tests are the most commonly reported preclinical pain tests in the CIA model (Gao et al., 2015; Impellizzeri et al., 2013; Inglis et al., 2007b), in our hands, behavior in either test was highly variable across cohorts. Therefore, we also piloted grip strength, which may discern CIA-induced loss of muscle function. In the grip strength test, a mouse is inverted on a wire cage bottom and the latency to fall from the wire is measured (Hutter-Saunders, Gendelman, \& Mosley, 2012). We found the paw swelling interferes with the ability to grip the wire, as CIA mice showed a significant reduction in latency to fall from the wire that was unaffected by JZL184 treatment (please see Appendix A).

The overall goal of the present study was to find a subeffective dose of the steroid DEX to combine with the MAGL inhibitor JZL184 to reduced CIA-induced pain and inflammation. The steroid DEX is a well-known anti-inflammatory drug that attenuates CIA-induces paw swelling (Inglis et al., 2007a; Kawalkowska et al., 2016) and proinflammatory cytokines (e.g., IL-1 $\beta$, TNF $\alpha$, IL-6, \& IL-17) in the serum of RA patients and rats subjected to CIA (Colin et al., 2010; Pu et al., 2016; Schlaghecke et al., 1994). Furthermore, DEX attenuates LPS-induced paw 
edema and tissue increase of the proinflammatory cytokines IL-1 $\beta$ and TNF $\alpha$ (Naidu, Kinsey, Guo, Cravatt, \& Lichtman, 2010). Due to its potent anti-inflammatory effects, it was difficult to select a subeffective dose of DEX in the present study. After running two dose response curves it was determined that $\mathrm{DEX}(\geq 0.03125 \mathrm{mg} / \mathrm{kg})$ attenuates CIA-induced paw swelling and increase in paw cytokine levels. DEX $(0.015625 \mathrm{mg} / \mathrm{kg})$ did not reduce CIA-induced arthritic clinical scores, mechanical allodynia, or thermal hyperalgesia and therefore, was chosen as the dose coadministered with JZL184.

We confirmed data from published reports that high dose DEX attenuates CIA inflammation, including paw swelling, clinical scores, and proinflammatory cytokine levels (Inglis et al., 2007a; Kawalkowska et al., 2016; Pu et al., 2016). We extended these findings by demonstrating that repeated DEX $(0.5 \mathrm{mg} / \mathrm{kg})$ administration also attenuates CIA-induced mechanical allodynia and thermal hyperalgesia. The observed analgesic and anti-inflammatory effects of DEX on inflammatory pain and paw swelling in the chronic CIA model is consistent with previous literature that DEX attenuates pain and edema in acute models of inflammatory pain (S. H. Ferreira et al., 1997; Naidu et al., 2010; Sasso et al., 2012). The present data, together with previous studies, suggest that DEX attenuates both chronic and acute inflammatory pain and inflammation. However, from a practical point of view, steroid hormones are not a viable longterm treatment for RA, especially at high doses, due to their harmful side effects such as metabolic problems, adrenal insufficiency, osteoporosis, and mood changes (Nelson, 2011).

Therefore, the third goal of the present study was to coadminister subeffective doses of the MAGL inhibitor JZL184 and the steroid DEX to attenuated CIA-induced arthritic signs while mitigating aversive side effects. The combination of low doses of JZL184 and DEX attenuated arthritic clinical scores in the present study, but the combination group did not differ from the 
DEX treated group, which indicates that the observed anti-inflammatory effect was likely driven by DEX and not JZL184. Although two dose response curves of DEX were run in present study, it is plausible that an even lower dose of DEX than we selected would yield a clearer coadministration effect. Indeed, despite the lack of a reduction in arthritic clinical scores by DEX $(0.015625 \mathrm{mg} / \mathrm{kg})$ in the dose response curve in Exp 1b, this same DEX dose did attenuate paw swelling in Exp 2. In support of the idea that DEX drove the anti-inflammatory effects, other labs have reported that glucocorticoids dominate the attenuation of CIA-induced paw swelling in combined treatments (Joosten et al., 1999; Kang, Lee, \& Lee, 2000; Kawalkowska et al., 2016). For example, dual administration of DEX $(0.25$ or $0.025 \mathrm{mg} / \mathrm{kg})$ and the anti-inflammatory cytokine IL-4 reduced paw inflammation, whereas IL-4 alone was ineffective, suggesting that the anti-inflammation was predominantly driven by DEX (Kang et al., 2000; Kawalkowska et al., 2016). When DEX is repeatedly administered and then administration in halted, mice subjected to CIA demonstrate a "rebound" effect with exaggerated paw swelling once DEX is withheld (Kang et al., 2000; Kawalkowska et al., 2016). Interestingly, mice administered the dual DEX/IL-4 treatment had less of a rebound of paw swelling than mice in the DEX-only treatment (Kawalkowska et al., 2016). These data indicate that, although DEX may dominate the antiinflammatory effects of combined treatment, it is plausible that dual administration with another anti-inflammatory mediator may continue to reduce inflammation after DEX treatment is terminated. Steroid discontinuation-induced inflammation is problematic for patients of chronic inflammatory disorders because steroids are recommended only for short-term use due to their aversive side effects (Singh et al., 2016). Unfortunately, in the present study the protection of JZL184 against DEX discontinuation-induced inflammation was not tested because paw tissue was harvested to determine for cytokines, but the idea of MAGL inhibition protecting from 
"steroid rebound" warrants further investigation. For example, mice may be subjected to CIA and administered DEX (as in Exp 1b) with or without JZL184. When DEX administration is suspended, a rebound effect (e.g., paw swelling) would be expected in DEX-treated mice, but JZL184 may attenuate such paw swelling.

Only one dose of JZL184/DEX coadministration was tested in the present study due to time and expense constraints, but it would be worth exploring multiple doses of JZL184/DEX for dual administration. The goal of the present study was to combine subeffective doses of both drugs to attenuate CIA-induced pain and inflammation to the same degree as an effective dose of either drug alone. Nevertheless, coadministration of subeffective doses of JZL184/DEX only reduced arthritic clinical scores. Although solo DEX attenuated CIA-induced inflammation and pain at high doses, aversive side effects limit the use of steroids in a clinical setting (Ravindran et al., 2009). However, solo JZL184 partially attenuated CIA-induced increase in paw cytokine levels at the 8 , but not $4 \mathrm{mg} / \mathrm{kg}$ dose. Therefore, subeffective DEX combined with a partially effective dose of JZL184 (i.e., $8 \mathrm{mg} / \mathrm{kg}$ ) may yield a greater anti-arthritic effect compared to only a subeffective dose of JZL184, while limiting the risks associated with steroid use.

Although dual administration of JZL184 and DEX did not attenuate the CIA-induced increase in paw pro- and anti-inflammatory cytokine levels, the combination treatment partially attenuated MPO, a marker of neutrophil activation. This blunted MPO response may indicate that JZL184/DEX attenuates paw swelling by reducing immune cell activation, rather than by decreasing immune cell signaling. To better address this hypothesis, it would be interesting to quantify paw levels of different types of immune cell using flow cytometry. Dual administration of DEX/IL-4 decreases the amount of pro-inflammatory Th-17 cells, while increasing the amount of anti-inflammatory Treg cells (Kawalkowska et al., 2016). Thus, in addition to 
decreasing neutrophil activity, the combination of JZL184/DEX may also attenuate the activity of other immune cells involved in RA, including macrophages, T cells, and B cells.

Due to the decrease in CIA-induced paw swelling by coadministration of JZL184/DEX future studies may also investigate joint tissue damage, using histology. Previous reports indicate that FAAH inhibition or $\mathrm{CB}_{2}$ receptor agonism attenuates paw swelling and joint degradation (Fukuda et al., 2014; Gui et al., 2015; Kinsey et al., 2011b). These data, along with the present study, suggest that dual administration of JZL184/DEX may also reduce CIA-induced joint damage.

A potential limitation of this study is that the dosing schedule was prophylactic and mice received drug treatment prior to the development of paw swelling. Prophylactic treatments are important for a variety of medical conditions that have an increased likelihood of occurring, including thromboembolic disease or infection after surgeries (Alhassan et al., 2017; Enzler, Berbari, \& Osmon, 2011). Further, vaccines are a major source of preventative treatments (Rappuoli, Pizza, Del Giudice, \& De Gregorio, 2014). However, most disorders are not detectable until the symptoms are present, and therefore must be treated therapeutically. In preclinical research both types of designs offer distinct advantages. Therapeutic dosing regiments are crucial in preclinical models to increase translatability to many human medical disorders. However, investigating preventative treatment is also useful in preclinical research. Although translatability is essential, it also is important to know if an effect is worth pursing further. In the present study there was a lack of an anti-inflammatory or analgesic effect after preventative treatment with the combination of JZL184 and DEX. Given that JZL/DEX could not prevent paw inflammation from developing, it is unlikely that dual administration would be antiinflammatory after paw inflammation was already present. 
A significant limitation of the CIA model chosen for the present study is that there was insufficient CIA induction of allodynia or hyperalgesia to determine the potential analgesic effects of dual JZL184/DEX treatment. In addition to the behavioral tests used, another potential reason for the inconsistent pain behavior is the CIA model itself. Although CIA is a great model of inflammatory arthritis, due to the strong similarities in pathogenesis with RA, there are many complicating factors in this model that make it difficult to use. For example, the presence of paw swelling is an obvious indication of collagen exposure. In the present study this was mitigated by blinding the experimenter to drug treatment, but due to the nature of the behavioral assays and paw swelling measurements it is impossible to blind an experimenter to the presence of paw swelling. Another limitation is that some of the mice immunized to collagen never develop paw swelling (Brand et al., 2007). The incidence of paw swelling in non-drug treated mice in our lab is typically above $80 \%$, but there is considerable variance between experiments, a reflection of the variance of CIA responses between mouse cohorts. Furthermore, swelling across paws is not uniform in each individual mouse and paw swelling across mice is inconsistent. Multiple methodological refinements were made to increase consistency across cohorts. We also tried to mitigate inconsistencies across cohorts of mice by having only one rater across all experiments to increases internal reliability. Although interrater reliabilities were conducted periodically to minimize drift, having only one rater may decrease reproducibility. A possible remedy to the problem of variance in swelling across paws and incidence across cohorts is to trade the strong mechanistic link between RA and CIA for more control within each experiment by using a different model of inflammatory arthritis.

In contrast to the CIA model, which is mainly used to research RA immunosuppressant treatments, injection of an inflammatory mediator into the footpad is extensively used to 
characterize chronic inflammatory pain (Ghasemlou, Chiu, Julien, \& Woolf, 2015; Inglis et al., 2007b). For example, intraplantar injection of CFA (without collagen, as is used in the CIA model) into the hind paw footpad of rodents induces chronic inflammatory pain in the injected paw, but not contralateral paw (Bagdas, AlSharari, Freitas, Tracy, \& Damaj, 2015). Although intraplantar injection of an inflammatory agent induces fairly consistent edema and swelling across animals, the immune response does not activate lymphocytes of the adaptive immune system, and thus does not model the autoimmune response germane to rheumatoid arthritis RA (Ghasemlou et al., 2015). This disconnect between inflammatory research and pain research limits external validity and translational potential. For example, many immunosuppressant treatments for RA are ineffective at attenuating pain (Lee, 2013). Data from our lab indicate that the $\mathrm{CB}_{2}$ receptor agonist $\mathrm{HU}-308$ attenuates CIA-induces paw swelling, but has no effect on allodynia; whereas HU-308 attenuates CFA-induced hyperalgesia, but not paw edema (see Appendix B). These data indicate the importance of incorporating behavioral tests into traditional models of inflammatory arthritis to develop novel treatments for RA that reduce both pain and inflammation.

Another alternative to the CIA model that is gaining popularity among inflammatory arthritis researchers is the collagen-antibody-induced arthritis (CAIA) model. In the classic CIA model, antibodies to self-collagen are produced by the mice. In the CAIA model, arthritis is induced by administration of these anti-collagen antibodies, along with immune stimulation by the gram-negative bacterial marker lipopolysaccharide (Kagari, Doi, \& Shimozato, 2002). Swelling develops in one or more paws within 10 days and lasts approximately three weeks. Inflammation eventually leads to cartilage and bone destruction, similar to CIA and RA. The major benefit of CAIA is that the time course is more rapid than in CIA, but unlike RA and CIA 
the joint inflammation in the CAIA model is not perpetuated by the T-cells of the adaptive immune system that are important in the induction of autoimmune disorders (Asquith et al., 2009; Kagari et al., 2002). We conducted a pilot study using the CAIA model (see Appendix C), but unfortunately the CAIA mice did not develop significant paw swelling compared to nonCAIA control mice, and thus MAGL inhibition was not anti-inflammatory. We consulted with the vendor, who was unable to explain the lack of arthritic development. Regardless, CAIA is reported to induce arthritis in multiple mouse strains that are resistant to CIA, as well as females (Khachigian, 2006). Thus, CAIA may offer broader opportunities to investigate cannabinoid effects on inflammatory arthritis, for example using genetic knockout mice that do not express MAGL.

In summary, we found that MAGL inhibition partially reduces paw inflammation caused by collagen-induced arthritis. This is the first demonstration of an anti-inflammatory effect of MAGL inhibition and an analgesic effect of DEX in a chronic inflammatory joint pain model. As previously demonstrated, the synthetic glucocorticoid dexamethasone was a potent antiinflammatory agent. Overall, the effects of either drug varied by test, by model, and by cohort. This variance may explain why behavioral data are rarely reported in the preclinical inflammatory arthritis literature. Given the strong negative side effects of current arthritis treatments, including but not limited to repeated steroid administration, the evidence that MAGL inhibition had anti-inflammatory effects is encouraging and merits additional investigation. 


\section{Acknowledgements}

I want to express my gratitude to my advisor, Dr. Steven Kinsey, for his mentorship and support throughout my doctoral studies. I would like to thank my dissertation committee for their assistance and input on my research. I also want to thank the Kinsey Lab, particularly Dr. Molly Crowe and Kristen Trexler, for all their help and friendship. I am also grateful to my family for all their support. This project was supported financially by the National Institutes of Health [R15 AR066806, U54GM104942]. 


\section{References}

Abbas, A. K., Litchman, A. H., \& Pober, J. S. (2002). Cellular and molecular immunology (4th ed.). Philadelphia, PA: W.B. Saunders Company.

Ahn, K., McKinney, M. K., \& Cravatt, B. F. (2008). Enzymatic pathways that regulate endocannabinoid signaling in the nervous system. Chem Rev, 108(5), 1687-1707. doi: $10.1021 / \mathrm{cr} 0782067$

Al-Abd, A. M., Al-Abbasi, F. A., Nofal, S. M., Khalifa, A. E., Williams, R. O., El-Eraky, W. I., . .. Abdel-Naim, A. B. (2014). Nimesulide improves the symptomatic and disease modifying effects of leflunomide in collagen induced arthritis. PLoS One, 9(11), e111843. doi: 10.1371/journal.pone.0111843

Alhassan, S., Pelinescu, A., Gandhi, V., Naddour, M., Singh, A. C., \& Bihler, E. (2017). Clinical Presentation and Risk Factors of Venous Thromboembolic Disease. Crit Care Nurs $Q$, 40(3), 201-209. doi: 10.1097/CNQ.0000000000000159

Asquith, D. L., Miller, A. M., McInnes, I. B., \& Liew, F. Y. (2009). Animal models of rheumatoid arthritis. Eur J Immunol, 39(8), 2040-2044. doi: 10.1002/eji.200939578

Bagdas, D., AlSharari, S. D., Freitas, K., Tracy, M., \& Damaj, M. I. (2015). The role of alpha5 nicotinic acetylcholine receptors in mouse models of chronic inflammatory and neuropathic pain. Biochem Pharmacol, 97(4), 590-600. doi: 10.1016/j.bcp.2015.04.013

Blake, D. R., Robson, P., Ho, M., Jubb, R. W., \& McCabe, C. S. (2006). Preliminary assessment of the efficacy, tolerability and safety of a cannabis-based medicine (Sativex) in the treatment of pain caused by rheumatoid arthritis. Rheumatology (Oxford), 45(1), 50-52. doi: 10.1093/rheumatology/kei183 
Blankman, J. L., Simon, G. M., \& Cravatt, B. F. (2007). A comprehensive profile of brain enzymes that hydrolyze the endocannabinoid 2-arachidonoylglycerol. Chem Biol, 14(12), 1347-1356. doi: 10.1016/j.chembiol.2007.11.006

Boissier, M. C., Semerano, L., Challal, S., Saidenberg-Kermanac'h, N., \& Falgarone, G. (2012). Rheumatoid arthritis: from autoimmunity to synovitis and joint destruction. J Autoimmun, 39(3), 222-228. doi: 10.1016/j.jaut.2012.05.021

Brand, D. D., Latham, K. A., \& Rosloniec, E. F. (2007). Collagen-induced arthritis. Nat Protoc, 2(5), 1269-1275. doi: 10.1038/nprot.2007.173

Brooks, S., Higgs, G., Jones, L., \& Dunnett, S. B. (2012). Longitudinal analysis of the behavioural phenotype in $\mathrm{Hdh}(\mathrm{CAG}) 150$ Huntington's disease knock-in mice. Brain Res Bull, 88(2-3), 182-188. doi: 10.1016/j.brainresbull.2010.05.004

Cabral, G. A., Raborn, E. S., Griffin, L., Dennis, J., \& Marciano-Cabral, F. (2008). CB2 receptors in the brain: role in central immune function. Br J Pharmacol, 153(2), 240-251. doi: 10.1038/sj.bjp.0707584

Caccese, R. G., Zimmerman, J. L., \& Carlson, R. P. (1992). Bacterial lipopolysaccharide potentiates type II collagen-induced arthritis in mice. Mediators Inflamm, 1(4), 273-279. doi: $10.1155 / \mathrm{S} 0962935192000425$

Chang, Y. H., Lee, S. T., \& Lin, W. W. (2001). Effects of cannabinoids on LPS-stimulated inflammatory mediator release from macrophages: involvement of eicosanoids. J Cell Biochem, 81(4), 715-723.

Chaplan, S. R., Bach, F. W., Pogrel, J. W., Chung, J. M., \& Yaksh, T. L. (1994). Quantitative assessment of tactile allodynia in the rat paw. J Neurosci Methods, 53(1), 55-63. 
Chen, J., Li, J., Gao, H., Wang, C., Luo, J., Lv, Z., \& Li, X. (2012). Comprehensive evaluation of different T-helper cell subsets differentiation and function in rheumatoid arthritis. $J$ Biomed Biotechnol, 2012, 535361. doi: 10.1155/2012/535361

Clayton, N., Marshall, F. H., Bountra, C., \& O'Shaughnessy, C. T. (2002). CB1 and CB2 cannabinoid receptors are implicated in inflammatory pain. Pain, 96(3), 253-260.

Colin, E. M., Asmawidjaja, P. S., van Hamburg, J. P., Mus, A. M., van Driel, M., Hazes, J. M., . .. Lubberts, E. (2010). 1,25-dihydroxyvitamin D3 modulates Th17 polarization and interleukin-22 expression by memory $\mathrm{T}$ cells from patients with early rheumatoid arthritis. Arthritis Rheum, 62(1), 132-142. doi: 10.1002/art.25043

Coutinho, A. E., \& Chapman, K. E. (2011). The anti-inflammatory and immunosuppressive effects of glucocorticoids, recent developments and mechanistic insights. Mol Cell Endocrinol, 335(1), 2-13. doi: 10.1016/j.mce.2010.04.005

Crowe, M. S., Leishman, E., Banks, M. L., Gujjar, R., Mahadevan, A., Bradshaw, H. B., \& Kinsey, S. G. (2015). Combined inhibition of monoacylglycerol lipase and cyclooxygenases synergistically reduces neuropathic pain in mice. Br J Pharmacol, 172(7), 1700-1712. doi: 10.1111/bph.13012

Crowe, M. S., Nass, S. R., Gabella, K. M., \& Kinsey, S. G. (2014). The endocannabinoid system modulates stress, emotionality, and inflammation. Brain Behav Immun, 42, 1-5. doi: 10.1016/j.bbi.2014.06.007

Enzler, M. J., Berbari, E., \& Osmon, D. R. (2011). Antimicrobial prophylaxis in adults. Mayo Clin Proc, 86(7), 686-701. doi: 10.4065/mcp.2011.0012

Ferreira, J. F., Ahmed Mohamed, A. A., \& Emery, P. (2016). Glucocorticoids and Rheumatoid Arthritis. Rheum Dis Clin North Am, 42(1), 33-46. doi: 10.1016/j.rdc.2015.08.006 
Ferreira, S. H., Cunha, F. Q., Lorenzetti, B. B., Michelin, M. A., Perretti, M., Flower, R. J., \& Poole, S. (1997). Role of lipocortin-1 in the anti-hyperalgesic actions of dexamethasone. Br J Pharmacol, 121(5), 883-888. doi: 10.1038/sj.bjp.0701211

Firestein, G. S. (2003). Evolving concepts of rheumatoid arthritis. Nature, 423(6937), 356-361. doi: 10.1038/nature01661

Fischer-Stenger, K., Updegrove, A. W., \& Cabral, G. A. (1992). D ${ }^{9}$-tetrahydrocannabinol decreases cytotoxic T lymphocyte activity to herpes simplex virus type 1 -infected cells. Proc. Soc. Exp. Biol. Med., 200, 422-430.

Frolov, A., Yang, L., Dong, H., Hammock, B. D., \& Crofford, L. J. (2013). Anti-inflammatory properties of prostaglandin E2: deletion of microsomal prostaglandin E synthase-1 exacerbates non-immune inflammatory arthritis in mice. Prostaglandins Leukot Essent Fatty Acids, 89(5), 351-358. doi: 10.1016/j.plefa.2013.08.003

Fukuda, S., Kohsaka, H., Takayasu, A., Yokoyama, W., Miyabe, C., Miyabe, Y., .. Nanki, T. (2014). Cannabinoid receptor 2 as a potential therapeutic target in rheumatoid arthritis. BMC Musculoskelet Disord, 15, 275. doi: 10.1186/1471-2474-15-275

Furst, D. E. (2010). The risk of infections with biologic therapies for rheumatoid arthritis. Semin Arthritis Rheum, 39(5), 327-346. doi: 10.1016/j.semarthrit.2008.10.002

Gao, X. H., Gao, R., Tian, Y. Z., McGonigle, P., Barrett, J. E., Dai, Y., \& Hu, H. (2015). A store-operated calcium channel inhibitor attenuates collagen-induced arthritis. $\mathrm{Br} J$ Pharmacol, 172(12), 2991-3002. doi: 10.1111/bph.13104

Ghasemlou, N., Chiu, I. M., Julien, J. P., \& Woolf, C. J. (2015). CD11b+Ly6G- myeloid cells mediate mechanical inflammatory pain hypersensitivity. Proc Natl Acad Sci U S A, 112(49), E6808-6817. doi: 10.1073/pnas.1501372112 
Ghosh, S., Wise, L. E., Chen, Y., Gujjar, R., Mahadevan, A., Cravatt, B. F., \& Lichtman, A. H. (2012). The monoacylglycerol lipase inhibitor JZL184 suppresses inflammatory pain in the mouse carrageenan model. Life Sci. doi: 10.1016/j.1fs.2012.06.020

Gui, H., Liu, X., Liu, L. R., Su, D. F., \& Dai, S. M. (2015). Activation of cannabinoid receptor 2 attenuates synovitis and joint distruction in collagen-induced arthritis. Immunobiology, 220(6), 817-822. doi: 10.1016/j.imbio.2014.12.012

Gui, H., Liu, X., Wang, Z. W., He, D. Y., Su, D. F., \& Dai, S. M. (2014). Expression of cannabinoid receptor 2 and its inhibitory effects on synovial fibroblasts in rheumatoid arthritis. Rheumatology (Oxford), 53(5), 802-809. doi: 10.1093/rheumatology/ket447

Haj, C. G., Sumariwalla, P. F., Hanus, L., Kogan, N. M., Yektin, Z., Mechoulam, R., ... Gallily, R. (2015). HU-444, a Novel, Potent Anti-Inflammatory, Nonpsychotropic Cannabinoid. J Pharmacol Exp Ther, 355(1), 66-75. doi: 10.1124/jpet.115.226100

Hanus, L., Breuer, A., Tchilibon, S., Shiloah, S., Goldenberg, D., Horowitz, M., . . Fride, E. (1999). HU-308: a specific agonist for CB(2), a peripheral cannabinoid receptor. Proc. Natl. Acad. Sci. U S A, 96(25), 14228-14233.

Hargreaves, K., Dubner, R., Brown, F., Flores, C., \& Joris, J. (1988). A new and sensitive method for measuring thermal nociception in cutaneous hyperalgesia. Pain, 32(1), 77-88.

Hillard, C. J. (2000). Biochemistry and pharmacology of the endocannabinoids arachidonylethanolamide and 2-arachidonylglycerol. Prostaglandins Other Lipid Mediat, 61(1-2), 3-18.

Holmdahl, R., Jansson, L., \& Andersson, M. (1986). Female sex hormones suppress development of collagen-induced arthritis in mice. Arthritis Rheum, 29(12), 1501-1509. 
Holmdahl, R., Tarkowski, A., \& Jonsson, R. (1991). Involvement of macrophages and dendritic cells in synovial inflammation of collagen induced arthritis in DBA/1 mice and spontaneous arthritis in MRL/lpr mice. Autoimmunity, 8(4), 271-280.

Hutter-Saunders, J. A., Gendelman, H. E., \& Mosley, R. L. (2012). Murine motor and behavior functional evaluations for acute 1-methyl-4-phenyl-1,2,3,6-tetrahydropyridine (MPTP) intoxication. J Neuroimmune Pharmacol, 7(1), 279-288. doi: 10.1007/s11481-011-92694

Ignatowska-Jankowska, B. M., Ghosh, S., Crowe, M. S., Kinsey, S. G., Niphakis, M. J., Abdullah, R. A., . . Lichtman, A. H. (2013). In vivo characterization of the highly selective monoacylglycerol lipase inhibitor KML29: Antinociceptive activity without cannabimimetic side effects. Br J Pharmacol. doi: 10.1111/bph.12298

Impellizzeri, D., Esposito, E., Di Paola, R., Ahmad, A., Campolo, M., Peli, A., . . Cuzzocrea, S. (2013). Palmitoylethanolamide and luteolin ameliorate development of arthritis caused by injection of collagen type II in mice. Arthritis Res Ther, 15(6), R192. doi: 10.1186/ar4382 Inglis, J. J., Criado, G., Medghalchi, M., Andrews, M., Sandison, A., Feldmann, M., \& Williams, R. O. (2007a). Collagen-induced arthritis in C57BL/6 mice is associated with a robust and sustained T-cell response to type II collagen. Arthritis Res Ther, 9(5), R113. doi: 10.1186/ar2319

Inglis, J. J., Notley, C. A., Essex, D., Wilson, A. W., Feldmann, M., Anand, P., \& Williams, R. (2007b). Collagen-induced arthritis as a model of hyperalgesia: functional and cellular analysis of the analgesic actions of tumor necrosis factor blockade. Arthritis Rheum, 56(12), 4015-4023. doi: 10.1002/art.23063 
Jansson, L., \& Holmdahl, R. (2001). Enhancement of collagen-induced arthritis in female mice by estrogen receptor blockage. Arthritis Rheum, 44(9), 2168-2175.

Joosten, L. A., Helsen, M. M., Saxne, T., Heinegard, D., van de Putte, L. B., \& van den Berg, W. B. (1999). Synergistic protection against cartilage destruction by low dose prednisolone and interleukin-10 in established murine collagen arthritis. Inflamm Res, 48(1), 48-55. doi: $10.1007 / \mathrm{s} 000110050396$

Kagari, T., Doi, H., \& Shimozato, T. (2002). The importance of IL-1 beta and TNF-alpha, and the noninvolvement of IL-6, in the development of monoclonal antibody-induced arthritis. J Immunol, 169(3), 1459-1466.

Kang, I., Lee, W. W., \& Lee, Y. (2000). Modulation of collagen-induced arthritis by IL-4 and dexamethasone: the synergistic effect of IL-4 and dexamethasone on the resolution of CIA. Immunopharmacology, 49(3), 317-324.

Karouzakis, E., Neidhart, M., Gay, R. E., \& Gay, S. (2006). Molecular and cellular basis of rheumatoid joint destruction. Immunol Lett, 106(1), 8-13. doi: 10.1016/j.imlet.2006.04.011

Kawalkowska, J. Z., Hemmerle, T., Pretto, F., Matasci, M., Neri, D., \& Williams, R. O. (2016). Targeted IL-4 therapy synergizes with dexamethasone to induce a state of tolerance by promoting Treg cells and macrophages in mice with arthritis. Eur J Immunol, 46(5), 1246-1257. doi: 10.1002/eji.201546221

Kerr, D. M., Harhen, B., Okine, B. N., Egan, L. J., Finn, D. P., \& Roche, M. (2013). The monoacylglycerol lipase inhibitor JZL184 attenuates LPS-induced increases in cytokine expression in the rat frontal cortex and plasma: differential mechanisms of action. $\mathrm{Br} J$ Pharmacol, 169(4), 808-819. doi: 10.1111/j.1476-5381.2012.02237.x 
Khachigian, L. M. (2006). Collagen antibody-induced arthritis. Nat Protoc, 1(5), 2512-2516. doi: 10.1038/nprot.2006.393

Kidd, B. L., \& Urban, L. A. (2001). Mechanisms of inflammatory pain. Br J Anaesth, 87(1), 311.

Kinsey, S. G., \& Cole, E. C. (2013). Acute Delta-tetrahydrocannabinol blocks gastric hemorrhages induced by the nonsteroidal anti-inflammatory drug diclofenac sodium in mice. Eur J Pharmacol. doi: 10.1016/j.ejphar.2013.06.001

Kinsey, S. G., Long, J. Z., O'Neal, S. T., Abdullah, R. A., Poklis, J. L., Boger, D. L., . . . Lichtman, A. H. (2009). Blockade of endocannabinoid-degrading enzymes attenuates neuropathic pain. Journal of Pharmacology and Experimental Therapeutics, 330(3), 902910. doi: jpet.109.155465 [pii] 10.1124/jpet.109.155465

Kinsey, S. G., Mahadevan, A., Zhao, B., Sun, H., Naidu, P. S., Razdan, R. K., . . Lichtman, A. H. (2011a). The $\mathrm{CB}(2)$ cannabinoid receptor-selective agonist $\mathrm{O}-3223$ reduces pain and inflammation without apparent cannabinoid behavioral effects. Neuropharmacology, 60(2-3), 244-251. doi: S0028-3908(10)00225-X [pii] 10.1016/j.neuropharm.2010.09.004

Kinsey, S. G., Naidu, P. S., Cravatt, B. F., Dudley, D. T., \& Lichtman, A. H. (2011b). Fatty acid amide hydrolase blockade attenuates the development of collagen-induced arthritis and related thermal hyperalgesia in mice. Pharmacol Biochem Behav, 99(4), 718-725. doi: S0091-3057(11)00221-8 [pii] 10.1016/j.pbb.2011.06.022

Kinsey, S. G., Nomura, D. K., O'Neal, S. T., Long, J. Z., Mahadevan, A., Cravatt, B. F., . . Lichtman, A. H. (2011c). Inhibition of monoacylglycerol lipase attenuates nonsteroidal anti-inflammatory drug-induced gastric hemorrhages in mice. Journal of Pharmacology and Experimental Therapeutics, 338(3), 795-802. doi: 10.1124/jpet.110.175778 
Kinsey, S. G., Wise, L. E., Ramesh, D., Abdullah, R., Selley, D. E., Cravatt, B. F., \& Lichtman, A. H. (2013). Repeated Low Dose Administration of the Monoacylglycerol Lipase Inhibitor JZL184 Retains CB1 Receptor Mediated Antinociceptive and Gastroprotective Effects. Journal of Pharmacology and Experimental Therapeutics. doi:

10.1124/jpet.112.201426

LaBuda, C. J., Koblish, M., \& Little, P. J. (2005). Cannabinoid CB2 receptor agonist activity in the hindpaw incision model of postoperative pain. Eur J Pharmacol, 527(1-3), 172-174. doi: 10.1016/j.ejphar.2005.10.020

Lee, Y. C. (2013). Effect and treatment of chronic pain in inflammatory arthritis. Curr Rheumatol Rep, 15(1), 300. doi: 10.1007/s11926-012-0300-4

Lichtman, A. H., Shelton, C. C., Advani, T., \& Cravatt, B. F. (2004). Mice lacking fatty acid amide hydrolase exhibit a cannabinoid receptor-mediated phenotypic hypoalgesia. Pain, 109(3), 319-327. doi: 10.1016/j.pain.2004.01.022

Lindstrom, T. M., \& Robinson, W. H. (2010). Rheumatoid arthritis: a role for immunosenescence? J Am Geriatr Soc, 58(8), 1565-1575. doi: 10.1111/j.1532$5415.2010 .02965 . x$

Long, J. Z., Li, W., Booker, L., Burston, J. J., Kinsey, S. G., Schlosburg, J. E., . . Cravatt, B. F. (2009). Selective blockade of 2-arachidonoylglycerol hydrolysis produces cannabinoid behavioral effects. Nat Chem Biol, 5(1), 37-44.

Lowin, T., Apitz, M., Anders, S., \& Straub, R. H. (2015). Anti-inflammatory effects of Nacylethanolamines in rheumatoid arthritis synovial cells are mediated by TRPV1 and TRPA1 in a COX-2 dependent manner. Arthritis Res Ther, 17, 321. doi: 10.1186/s13075015-0845-5 
Lowin, T., Pongratz, G., \& Straub, R. H. (2016). The synthetic cannabinoid WIN55,212-2 mesylate decreases the production of inflammatory mediators in rheumatoid arthritis synovial fibroblasts by activating CB2, TRPV1, TRPA1 and yet unidentified receptor targets. J Inflamm (Lond), 13, 15. doi: 10.1186/s12950-016-0114-7

Luo, Y., Boyle, D. L., Hammaker, D., Edgar, M., Franzoso, G., \& Firestein, G. S. (2011). Suppression of collagen-induced arthritis in growth arrest and DNA damage-inducible protein 45beta-deficient mice. Arthritis Rheum, 63(10), 2949-2955. doi: 10.1002/art.30497

Malfait, A. M., Gallily, R., Sumariwalla, P. F., Malik, A. S., Andreakos, E., Mechoulam, R., \& Feldmann, M. (2000). The nonpsychoactive cannabis constituent cannabidiol is an oral anti- arthritic therapeutic in murine collagen-induced arthritis. Proc Natl Acad Sci US A, 97(17), 9561-9566.

McInnes, I. B., \& Schett, G. (2007). Cytokines in the pathogenesis of rheumatoid arthritis. Nat Rev Immunol, 7(6), 429-442. doi: 10.1038/nri2094

McInnes, I. B., \& Schett, G. (2011). The pathogenesis of rheumatoid arthritis. N Engl J Med, 365(23), 2205-2219. doi: 10.1056/NEJMra1004965 10.7748/phc2011.11.21.9.29.c8797

Mechoulam, R., \& Parker, L. A. (2013). The endocannabinoid system and the brain. Annu Rev Psychol, 64, 21-47. doi: 10.1146/annurev-psych-113011-143739

Nagakura, Y., Okada, M., Kohara, A., Kiso, T., Toya, T., Iwai, A., . . Yamaguchi, T. (2003). Allodynia and hyperalgesia in adjuvant-induced arthritic rats: time course of progression and efficacy of analgesics. J Pharmacol Exp Ther, 306(2), 490-497. doi:

10.1124/jpet.103.050781 
Naidu, P. S., Kinsey, S. G., Guo, T. L., Cravatt, B. F., \& Lichtman, A. H. (2010). Regulation of inflammatory pain by inhibition of fatty acid amide hydrolase. Journal of Pharmacology and Experimental Therapeutics, 334(1), 182-190. doi: jpet.109.164806 [pii] 10.1124/jpet.109.164806

Nass, S. R. (2015). Analgesic and Anti-Inflammatory Effects of Monoacylglycerol Lipase Inhibition in Mice Subjected to Collagen-Induced Arthritis. Unpublished Master's Thesis.

Nathan, C. (2006). Neutrophils and immunity: challenges and opportunities. Nat Rev Immunol, 6(3), 173-182. doi: 10.1038/nri1785

Nell, V. P., Machold, K. P., Eberl, G., Stamm, T. A., Uffmann, M., \& Smolen, J. S. (2004). Benefit of very early referral and very early therapy with disease-modifying antirheumatic drugs in patients with early rheumatoid arthritis. Rheumatology (Oxford), 43(7), 906-914. doi: 10.1093/rheumatology/keh199

Nelson, R. J. (2011). An introduction to behavioral endocrinology (Fourth edition. ed.). Sunderland, Massachusetts :: Sinauer Associates.

Nieto, F. R., Clark, A. K., Grist, J., Chapman, V., \& Malcangio, M. (2015). Calcitonin generelated peptide-expressing sensory neurons and spinal microglial reactivity contribute to pain states in collagen-induced arthritis. Arthritis Rheumatol, 67(6), 1668-1677. doi: 10.1002/art.39082

Nilsson, K. E., Andren, M., Diaz de Stahl, T., \& Kleinau, S. (2009). Enhanced susceptibility to low-dose collagen-induced arthritis in CR1/2-deficient female mice--possible role of estrogen on CR1 expression. FASEB J, 23(8), 2450-2458. doi: 10.1096/fj.08-125849

Nishioku, T., Dohgu, S., Koga, M., Machida, T., Watanabe, T., Miura, T., . . Kataoka, Y. (2012). Cyclophilin A secreted from fibroblast-like synoviocytes is involved in the 
induction of CD147 expression in macrophages of mice with collagen-induced arthritis. $J$ Inflamm (Lond), 9(1), 44. doi: 10.1186/1476-9255-9-44

Pu, J., Fang, F. F., Li, X. Q., Shu, Z. H., Jiang, Y. P., Han, T., . . Zheng, C. J. (2016). Matrine Exerts a Strong Anti-Arthritic Effect on Type II Collagen-Induced Arthritis in Rats by Inhibiting Inflammatory Responses. Int J Mol Sci, 17(9). doi: 10.3390/ijms17091410

Rabb, H. (2002). The T cell as a bridge between innate and adaptive immune systems: implications for the kidney. Kidney Int, 61(6), 1935-1946. doi: 10.1046/j.15231755.2002.00378.x

Rappuoli, R., Pizza, M., Del Giudice, G., \& De Gregorio, E. (2014). Vaccines, new opportunities for a new society. Proc Natl Acad Sci U S A, 111(34), 12288-12293. doi: 10.1073/pnas.1402981111

Ravindran, V., Rachapalli, S., \& Choy, E. H. (2009). Safety of medium- to long-term glucocorticoid therapy in rheumatoid arthritis: a meta-analysis. Rheumatology (Oxford), 48(7), 807-811. doi: 10.1093/rheumatology/kep096

Richardson, D., Pearson, R. G., Kurian, N., Latif, M. L., Garle, M. J., Barrett, D. A., . . Chapman, V. (2008). Characterisation of the cannabinoid receptor system in synovial tissue and fluid in patients with osteoarthritis and rheumatoid arthritis. Arthritis Res Ther, 10(2), R43. doi: 10.1186/ar2401

Rioja, I., Bush, K. A., Buckton, J. B., Dickson, M. C., \& Life, P. F. (2004). Joint cytokine quantification in two rodent arthritis models: kinetics of expression, correlation of mRNA and protein levels and response to prednisolone treatment. Clin Exp Immunol, 137(1), 6573. doi: 10.1111/j.1365-2249.2004.02499.x 
Roudier, J. (2006). HLA-DRB1 genes and extraarticular rheumatoid arthritis. Arthritis Res Ther, 8(1), 103. doi: 10.1186/ar1886

Sasakawa, T., Sasakawa, Y., Ohkubo, Y., \& Mutoh, S. (2005). FK506 ameliorates spontaneous locomotor activity in collagen-induced arthritis: implication of distinct effect from suppression of inflammation. Int Immunopharmacol, 5(3), 503-510. doi:

10.1016/j.intimp.2004.10.012

Sasso, O., Bertorelli, R., Bandiera, T., Scarpelli, R., Colombano, G., Armirotti, A., ... Piomelli, D. (2012). Peripheral FAAH inhibition causes profound antinociception and protects against indomethacin-induced gastric lesions. Pharmacol Res, 65(5), 553-563. doi: 10.1016/j.phrs.2012.02.012

Schlaghecke, R., Beuscher, D., Kornely, E., \& Specker, C. (1994). Effects of glucocorticoids in rheumatoid arthritis. Diminished glucocorticoid receptors do not result in glucocorticoid resistance. Arthritis Rheum, 37(8), 1127-1131.

Schlosburg, J. E., Blankman, J. L., Long, J. Z., Nomura, D. K., Pan, B., Kinsey, S. G., .. . Cravatt, B. F. (2010). Chronic monoacylglycerol lipase blockade causes functional antagonism of the endocannabinoid system. Nat Neurosci, 13(9), 1113-1119. doi: nn.2616 [pii] 10.1038/nn.2616

Seki, N., Sudo, Y., Yoshioka, T., Sugihara, S., Fujitsu, T., Sakuma, S., . . Fujiwara, H. (1988). Type II collagen-induced murine arthritis. I. Induction and perpetuation of arthritis require synergy between humoral and cell-mediated immunity. J Immunol, 140(5), 14771484.

Selvi, E., Lorenzini, S., Garcia-Gonzalez, E., Maggio, R., Lazzerini, P. E., Capecchi, P. L., . . . Marcolongo, R. (2008). Inhibitory effect of synthetic cannabinoids on cytokine 
production in rheumatoid fibroblast-like synoviocytes. Clin Exp Rheumatol, 26(4), 574581.

Shahrara, S., Huang, Q., Mandelin, A. M., 2nd, \& Pope, R. M. (2008). TH-17 cells in rheumatoid arthritis. Arthritis Res Ther, 10(4), R93. doi: 10.1186/ar2477

Singh, J. A., Saag, K. G., Bridges, S. L., Jr., Akl, E. A., Bannuru, R. R., Sullivan, M. C., . . McAlindon, T. (2016). 2015 American College of Rheumatology Guideline for the Treatment of Rheumatoid Arthritis. Arthritis Rheumatol, 68(1), 1-26. doi: 10.1002/art.39480

Smith, M. D. (2011). The normal synovium. Open Rheumatol J, 5, 100-106. doi: $10.2174 / 1874312901105010100$

Sokka, T., Kankainen, A., \& Hannonen, P. (2000). Scores for functional disability in patients with rheumatoid arthritis are correlated at higher levels with pain scores than with radiographic scores. Arthritis Rheum, 43(2), 386-389. doi: 10.1002/15290131(200002)43:2<386::AID-ANR19>3.0.CO;2-Z

Sumariwalla, P. F., Gallily, R., Tchilibon, S., Fride, E., Mechoulam, R., \& Feldmann, M. (2004). A novel synthetic, nonpsychoactive cannabinoid acid (HU-320) with antiinflammatory properties in murine collagen-induced arthritis. Arthritis Rheum, 50(3), 985-998. doi: 10.1002/art.20050

Svensson, L., Jirholt, J., Holmdahl, R., \& Jansson, L. (1998). B cell-deficient mice do not develop type II collagen-induced arthritis (CIA). Clin Exp Immunol, 111(3), 521-526.

Takemura, S., Klimiuk, P. A., Braun, A., Goronzy, J. J., \& Weyand, C. M. (2001). T cell activation in rheumatoid synovium is B cell dependent. J Immunol, 167(8), 4710-4718. 
Terato, K., Hasty, K. A., Reife, R. A., Cremer, M. A., Kang, A. H., \& Stuart, J. M. (1992). Induction of arthritis with monoclonal antibodies to collagen. J Immunol, 148(7), 21032108.

Valenzano, K. J., Tafesse, L., Lee, G., Harrison, J. E., Boulet, J. M., Gottshall, S. L., . . . Whiteside, G. T. (2005). Pharmacological and pharmacokinetic characterization of the cannabinoid receptor 2 agonist, GW405833, utilizing rodent models of acute and chronic pain, anxiety, ataxia and catalepsy. Neuropharmacology, 48(5), 658-672. doi: S00283908(05)00009-2 [pii] 10.1016/j.neuropharm.2004.12.008

van Laar, M., Pergolizzi, J. V., Jr., Mellinghoff, H. U., Merchante, I. M., Nalamachu, S., O'Brien, J., . . Raffa, R. B. (2012). Pain treatment in arthritis-related pain: beyond NSAIDs. Open Rheumatol J, 6, 320-330. doi: 10.2174/1874312901206010320

Walsh, D. A., \& McWilliams, D. F. (2012). Pain in rheumatoid arthritis. Curr Pain Headache Rep, 16(6), 509-517. doi: 10.1007/s11916-012-0303-x

Williams, R. O., Feldmann, M., \& Maini, R. N. (1992). Anti-tumor necrosis factor ameliorates joint disease in murine collagen-induced arthritis. Proc Natl Acad Sci U S A, 89(20), 9784-9788. 
A

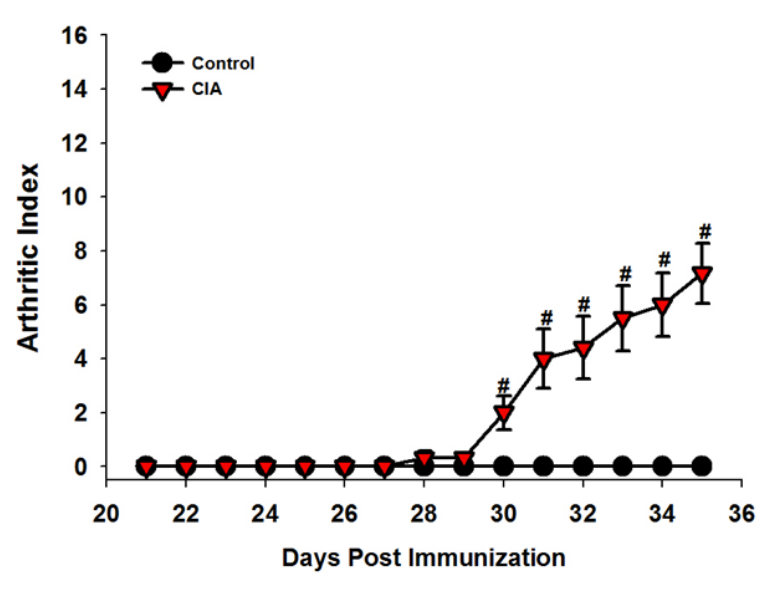

C

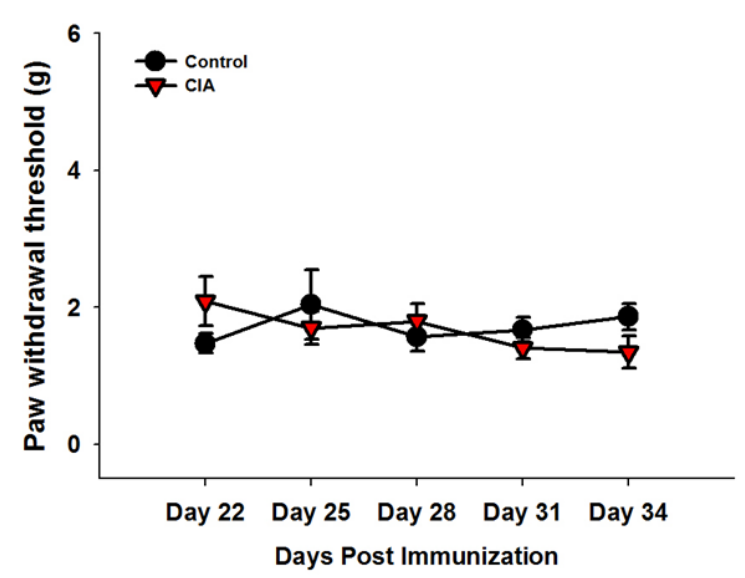

B Caliper Measurement

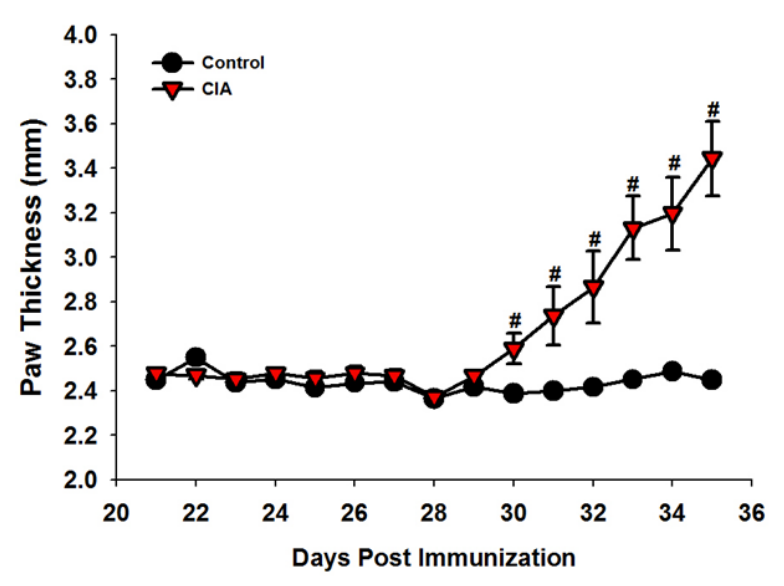

D

Plantar Stimulator Test

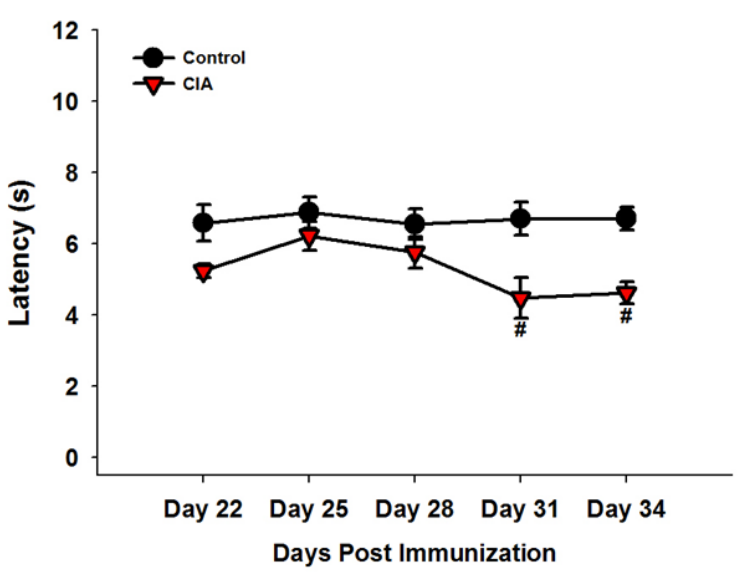

Figure 4. Collagen-induced arthritis (CIA) induces paw swelling and thermal hyperalgesia. Mice were administered an emulsion of collagen/CFA and then given a booster exposure to collagen 21 days later. Control mice were administered an emulsion of acetic acid/IFA. CIA mice developed an increase in arthritic clinical scores (A) and hind paw thickness (B). Mice were tested for pain-related behaviors on days 22, 25, 28, 31, and 34 post immunization. Mice did not develop mechanical allodynia tested via the von Frey assay (C), but did develop thermal hyperalgesia in the plantar stimulator test (D). Data expressed as mean $\pm \operatorname{SEM}(n=12)$. \# p < 0.05 vs. control mice. 
A

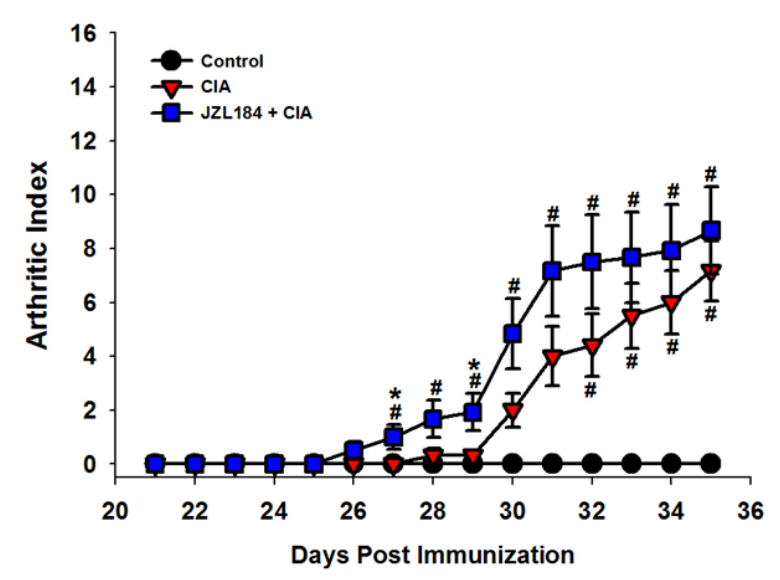

C
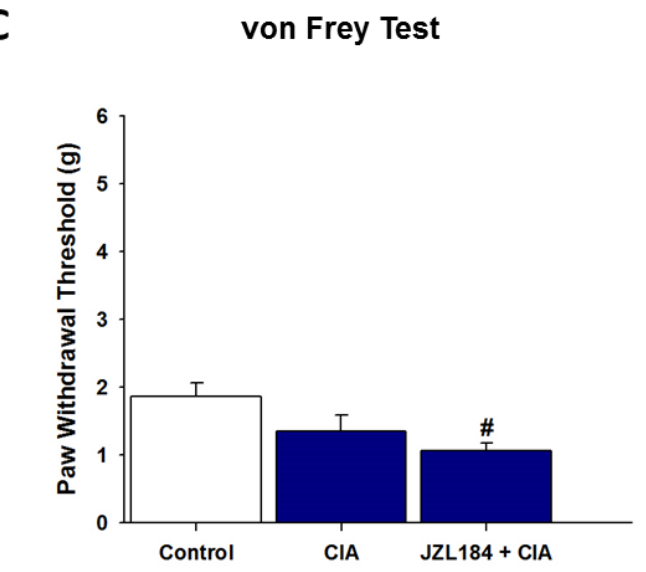

B Caliper Measurement

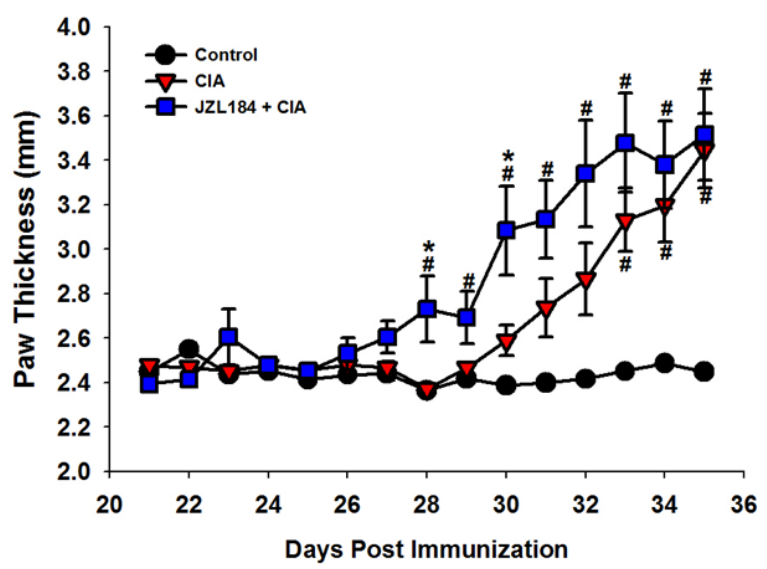

D Plantar Stimulator Test

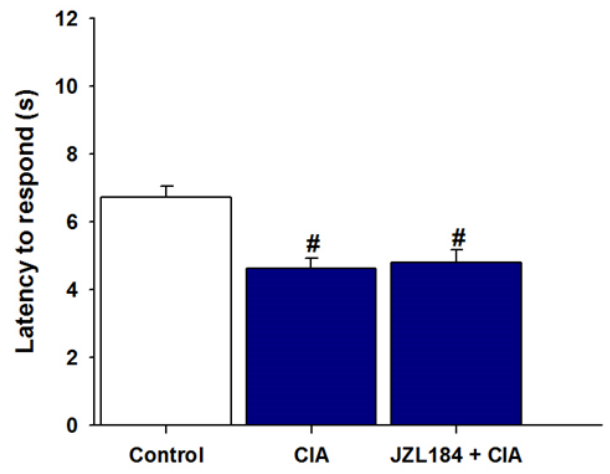

Figure 5. Repeated dosing of the MAGL inhibitor JZL184 ( $8 \mathrm{mg} / \mathrm{kg})$ did not affect paw swelling, allodynia, or hyperalgesia in mice subjected to CIA. Mice were administered JZL184 ( $8 \mathrm{mg} / \mathrm{kg}$, s.c.) or vehicle for 15 days. JZL184 did not attenuate CIA-induce paw swelling as measured by clinical scores (A) or paw thickness (B). CIA mice did not develop mechanical allodynia (C), but did develop thermal hyperalgesia (D). Data expressed as mean \pm SEM ( $n=$ 12). ${ }^{*} \mathrm{p}<0.05$ vs. CIA mice; $\# \mathrm{p}<0.05$ vs. control mice. 

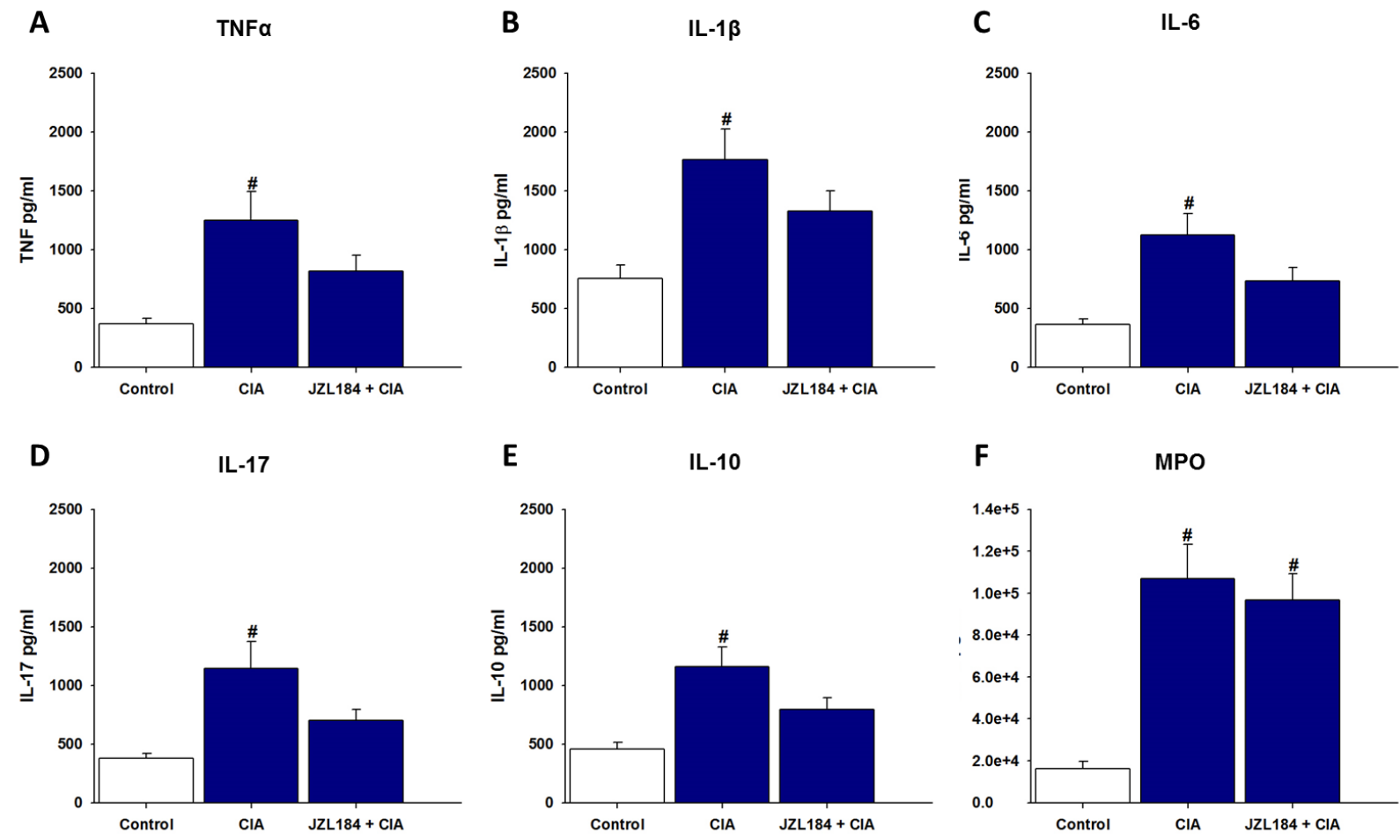

Figure 6. Repeated dosing of the MAGL inhibitor JZL184 (8 mg/kg) partially attenuated CIAinduced increase in paw levels of proinflammatory (TNF $\alpha$, IL-1 $\beta$, IL-6, and IL-17) (A-D) and anti-inflammatory (IL-10) (E) cytokines. JZL184 did not affect the CIA-induced increase in MPO (F), a marker of neutrophil activity. Mice were administered JZL184 or vehicle for 15 days. Data expressed as mean $\pm \operatorname{SEM}(n=12)$. $\# \mathrm{p}<0.05$ vs. control mice. 
A

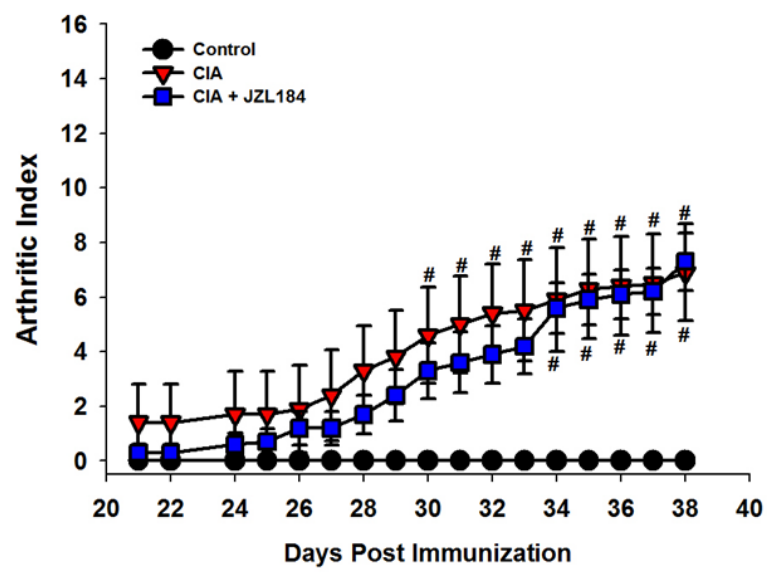

C von Frey Test

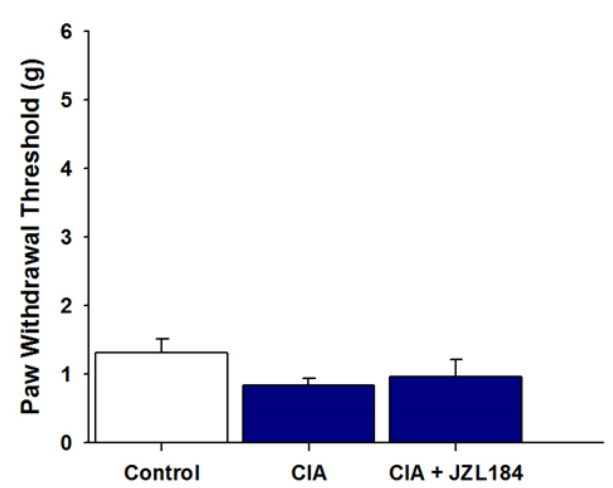

B Caliper Measurement

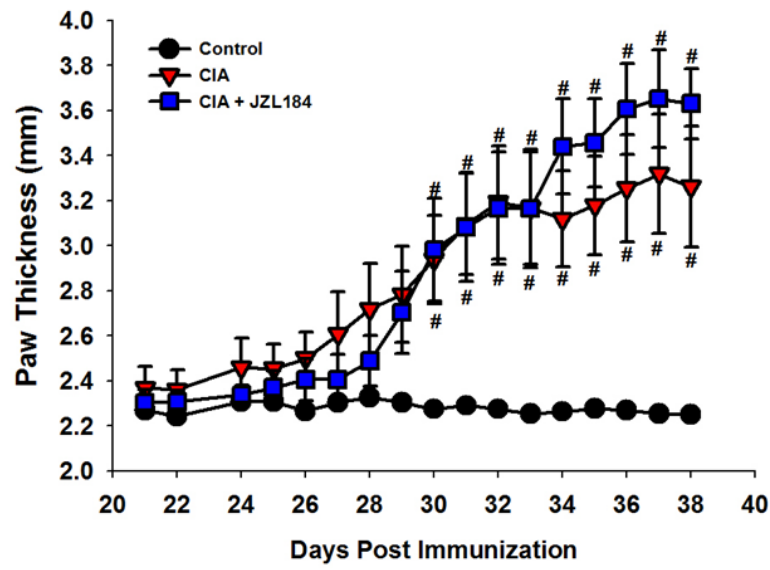

D

Plantar Stimulator Test

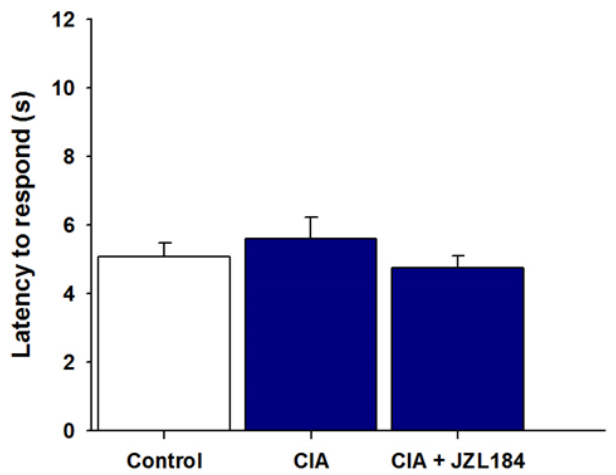

Figure 7. Repeated dosing of the MAGL inhibitor JZL184 (4 mg/kg) was subeffective at attenuating CIA-induced paw swelling. Mice were administered JZL184 or vehicle for 18 days. JZL184 did not attenuate the CIA-induce increase in arthritic clinical scores (A) or hind paw thickness (B). CIA mice did not develop mechanical allodynia (C) or thermal hyperalgesia (D). Data expressed as mean $\pm \operatorname{SEM}(n=10)$. $\# \mathrm{p}<0.05$ vs. control mice. 
A

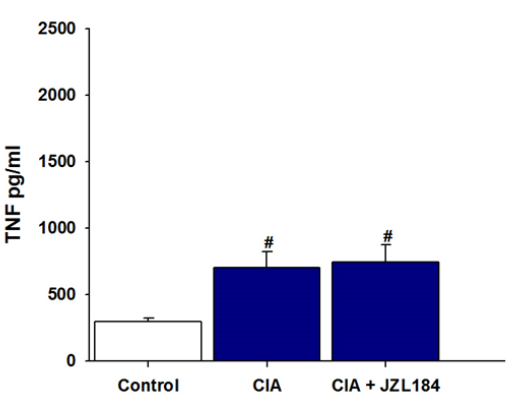

D

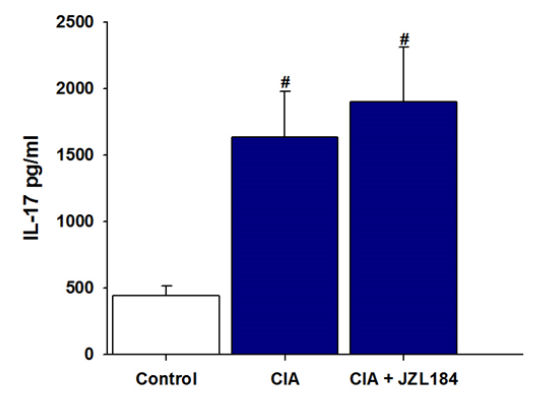

B

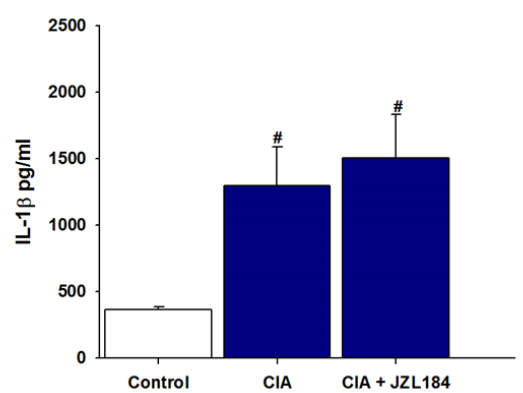

E

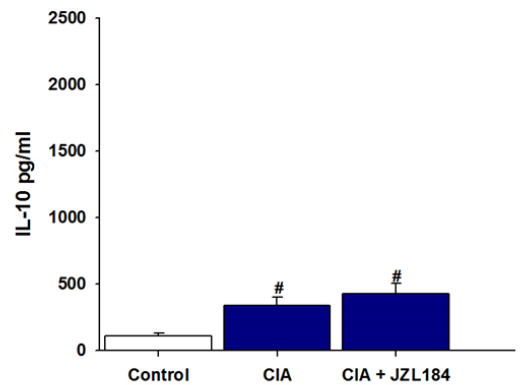

C

IL-6

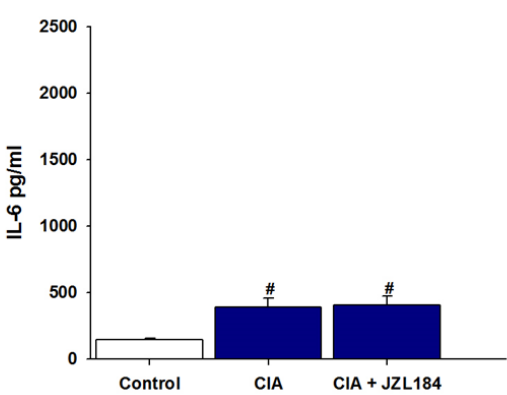

$\mathbf{F}$

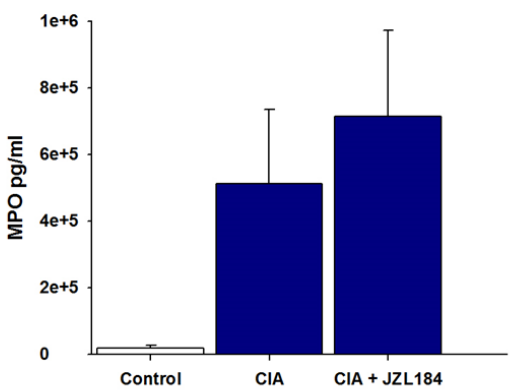

Figure 8. Repeated dosing of the MAGL inhibitor JZL184 (4 mg/kg) was subeffective at attenuating the CIA-induced increase in paw levels of proinflammatory (A-D) and antiinflammatory (E) cytokines. CIA did not increase paw MPO (F) levels. Mice were administered JZL184 or vehicle for 18 days. Data expressed as mean \pm SEM $(n=10)$. \# $p<0.05$ vs. control mice. 
A

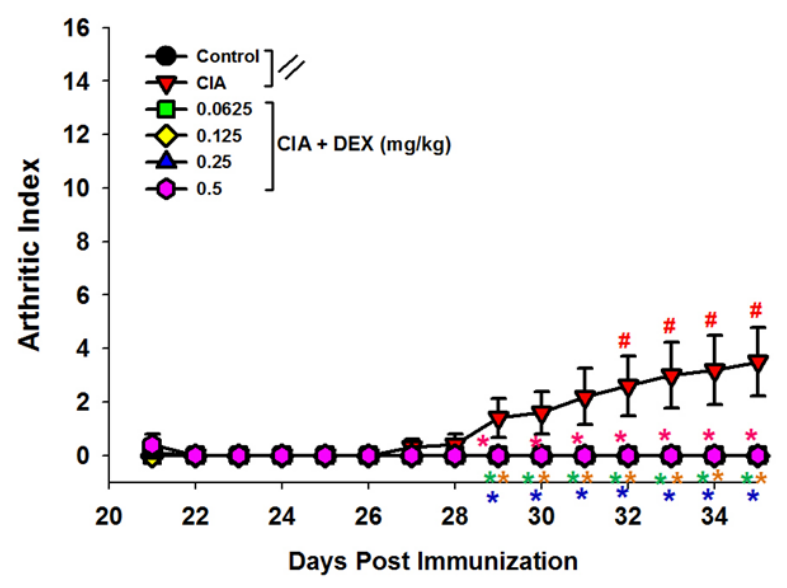

C

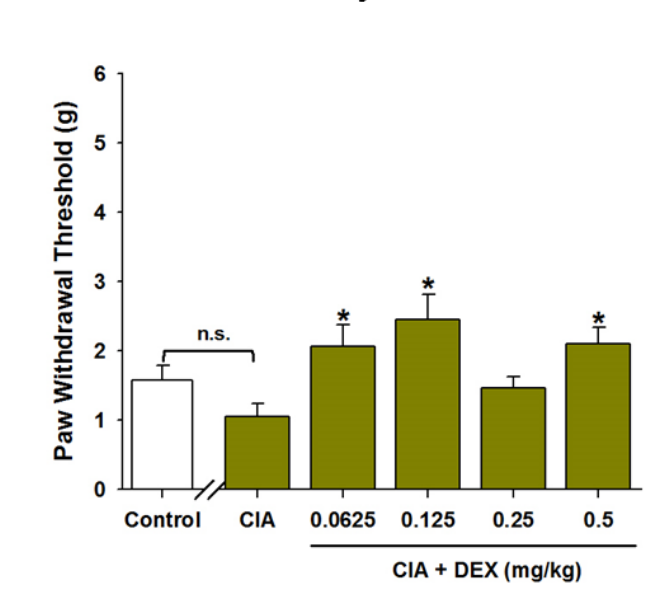

B Caliper Measurement

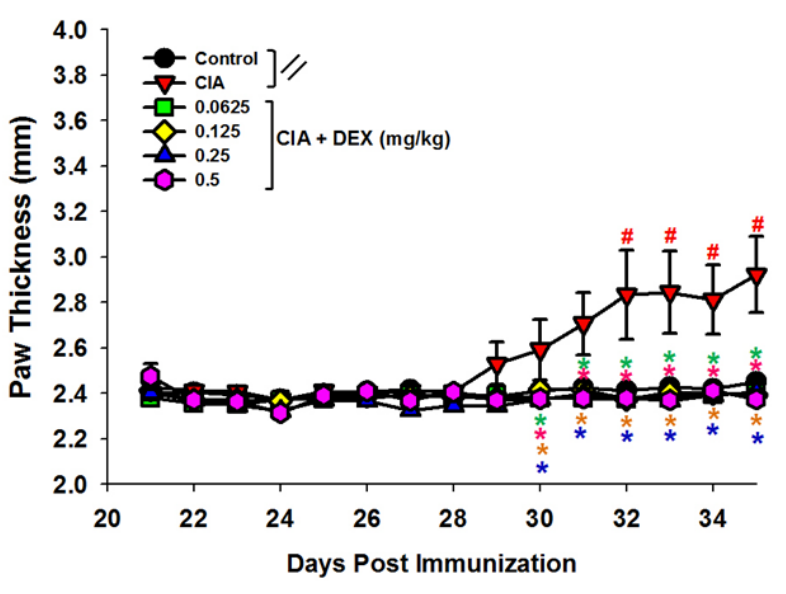

D Plantar Stimulator Test

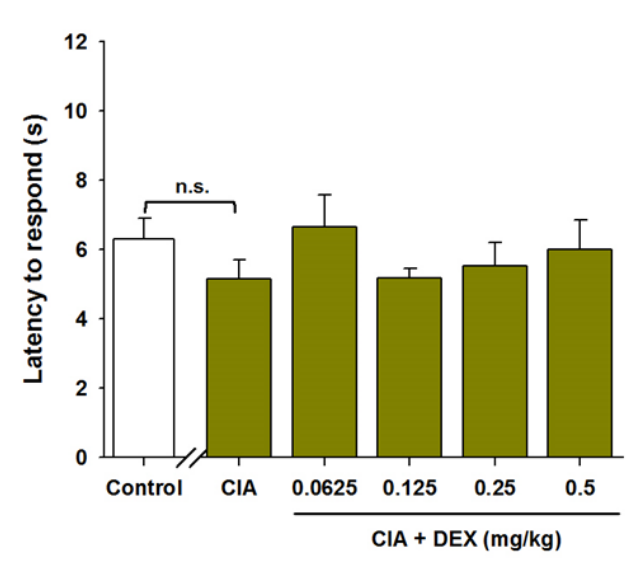

Figure 9. Repeated dosing of the steroid dexamethasone (DEX) attenuated paw swelling and allodynia, in mice subjected to CIA. Mice were administered DEX or vehicle once daily for 15 consecutive days. DEX attenuated CIA-induced clinical scores (A) or paw thickness (B). Although CIA did not induce mechanical allodynia, DEX attenuated mechanical allodynia (C). CIA did not induce thermal hyperalgesia in the plantar test (D). Data expressed as mean \pm SEM $(\mathrm{n}=9-10) .{ }^{*} \mathrm{p}<0.05$ vs. CIA mice; $\# \mathrm{p}<0.05$ vs. control mice. 


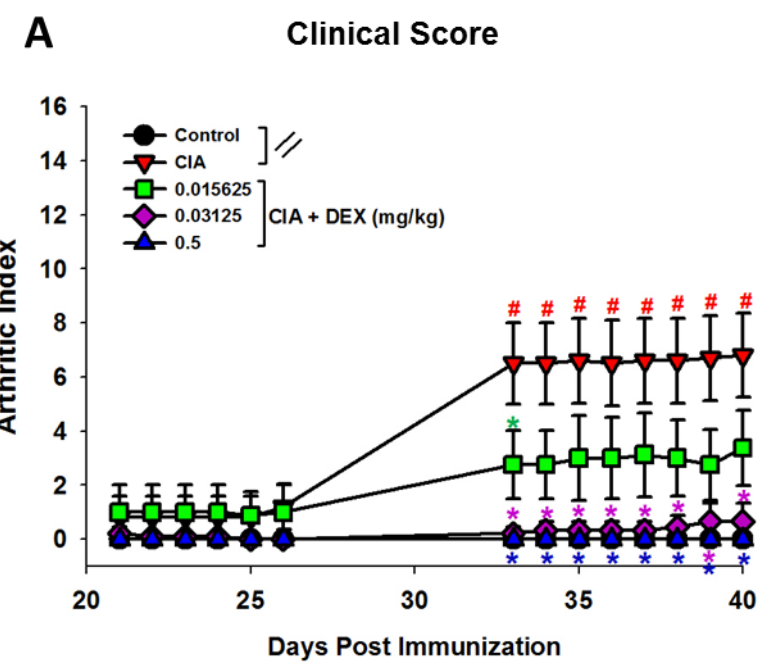

C von Frey Test

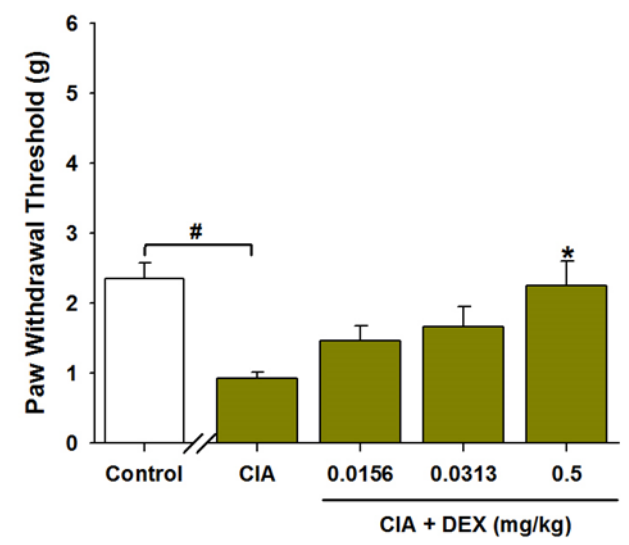

B Caliper Measurement

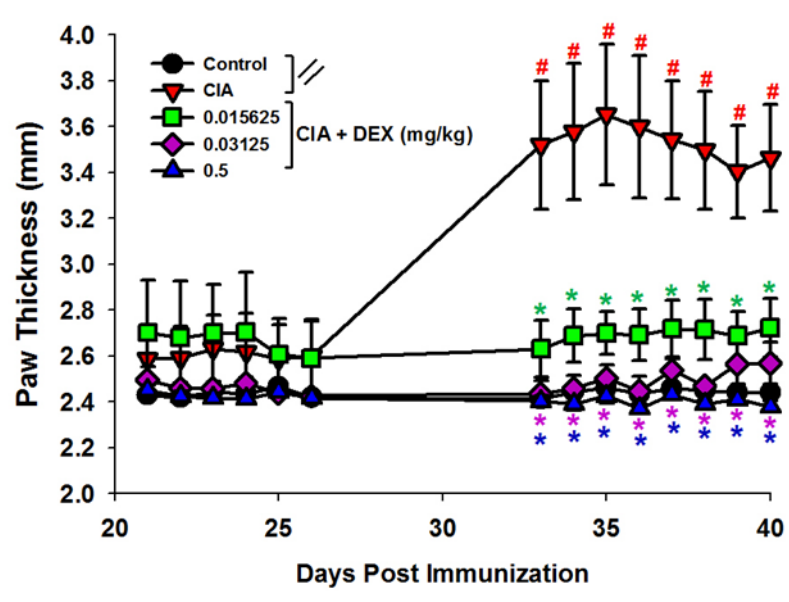

D

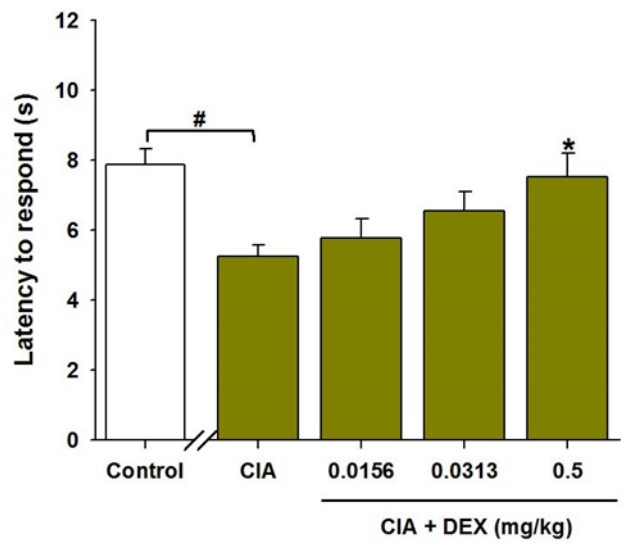

Figure 10. Repeated dosing of the steroid dexamethasone (DEX; $0.015625 \mathrm{mg} / \mathrm{kg}$ ) was subeffective at attenuating arthritic clinical scores and pain-related behavior in CIA mice. Mice were administered DEX or vehicle once daily for 20 days. DEX attenuated CIA-induced arthritic clinical scores (A) paw thickness (B), mechanical allodynia (C), and thermal hyperalgesia (D). Data expressed as mean $\pm \operatorname{SEM}(n=9-10) .{ }^{*} \mathrm{p}<0.05$ vs. CIA mice; $\# \mathrm{p}<0.05$ vs. control mice. 

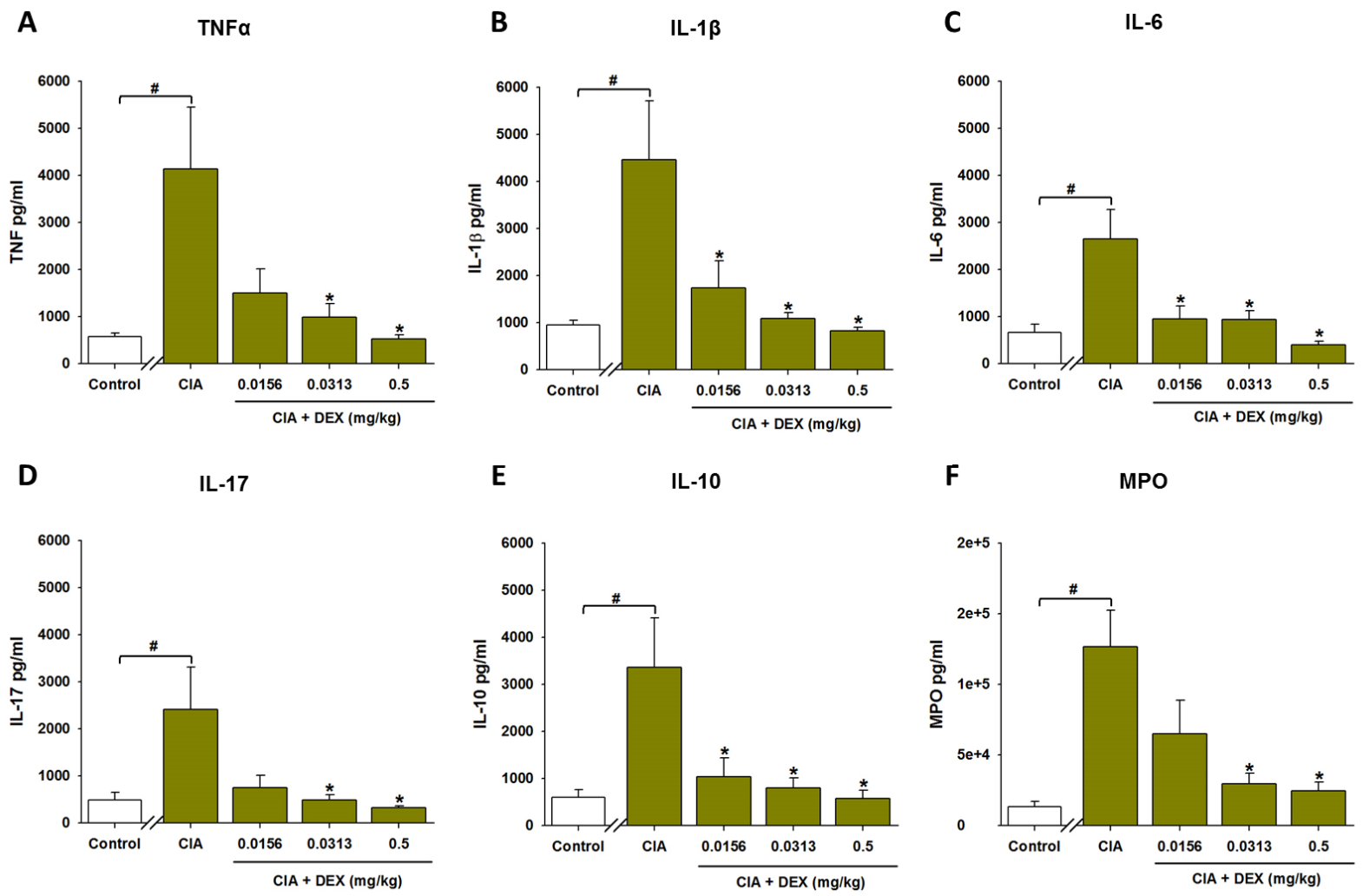

Figure 11. Repeated dosing of the steroid dexamethasone (DEX) was subeffective at attenuating the CIA-induced increase in proinflammatory cytokine (TNF $\alpha$ and IL-17) and MPO paw levels. Mice were administered DEX or vehicle once daily for 20 days. DEX attenuated the CIAinduced paw increase in proinflammatory cytokines (A-D) and the neutrophil marker MPO (F). Data expressed as mean \pm SEM $(n=9-10) . * p<0.05$ vs. vehicle CIA mice; $\# \mathrm{p}<0.05$ vs. control mice. 
A

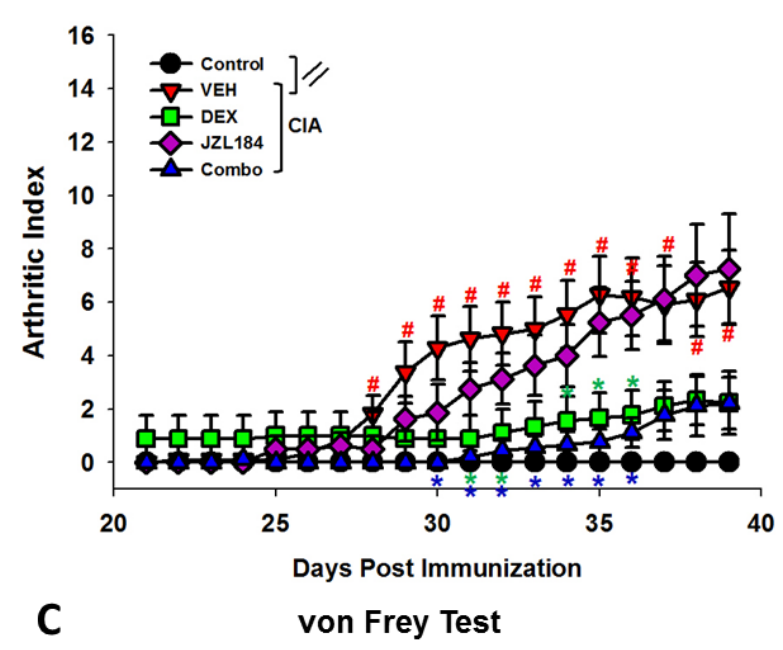

C

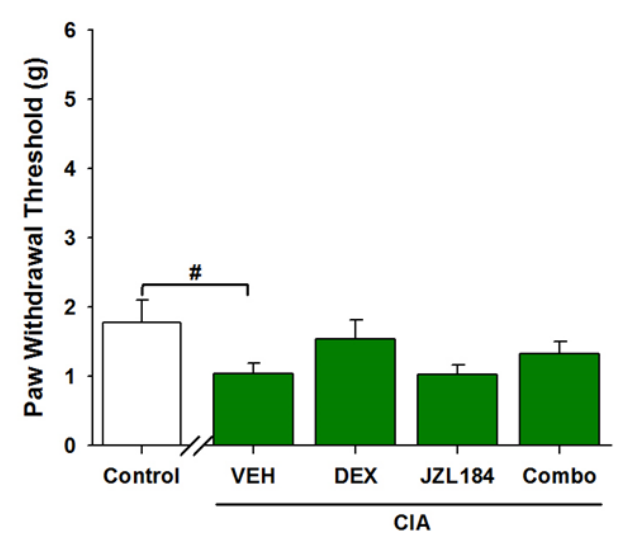

B Caliper Measurement

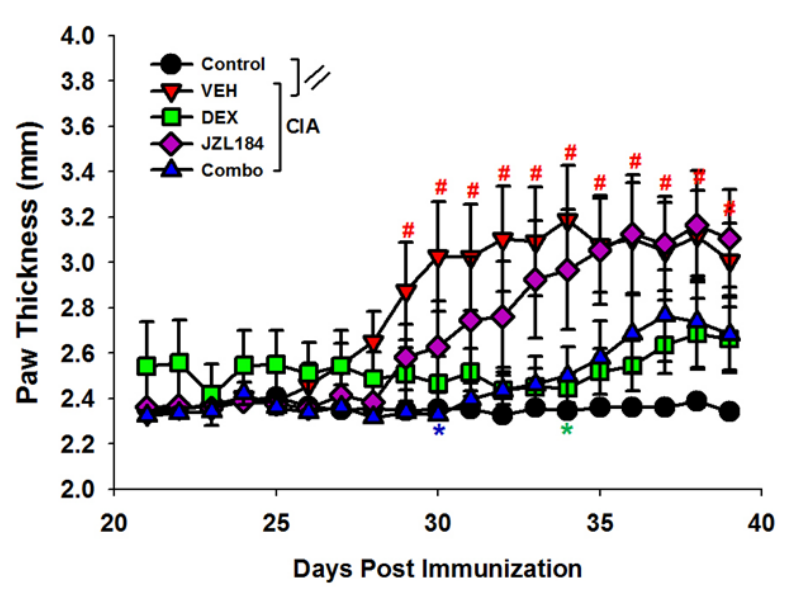

D Plantar Stimulator Test

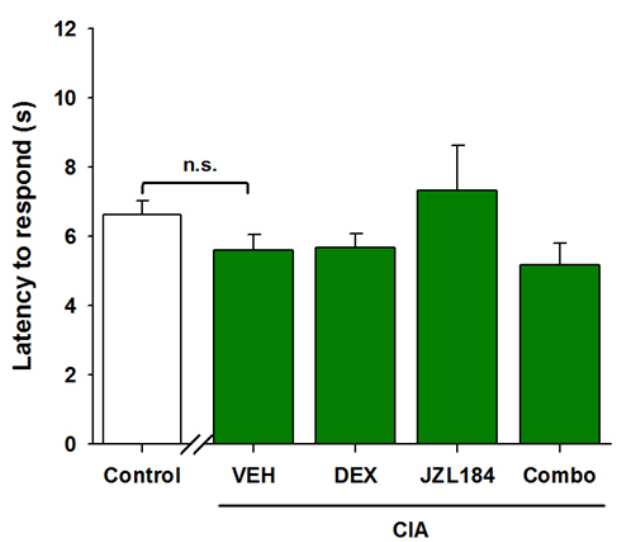

Figure 12. Repeated, dual administration of JZL184/DEX, or DEX alone, attenuated CIAinduced paw swelling. Mice were administered the JZL184 (4 mg/kg; s.c.), DEX (0.015625 $\mathrm{mg} / \mathrm{kg}$; s.c.), both JZL184 (4 mg/kg; s.c.) and DEX (0.015625 mg/kg; s.c.), or vehicle once daily for 19 days. DEX or JZL184/DEX attenuated CIA-induce arthritic clinical scores (A) and caliper measurements (B). CIA-induced mechanical allodynia (C) was not attenuated by drug treatment. There was no CIA-induced thermal hyperalgesia (D). Data expressed as mean \pm SEM ( $n=9-11)$. $* \mathrm{p}<0.05$ vs. CIA mice; \# $\mathrm{p}<0.05$ vs. control mice. 


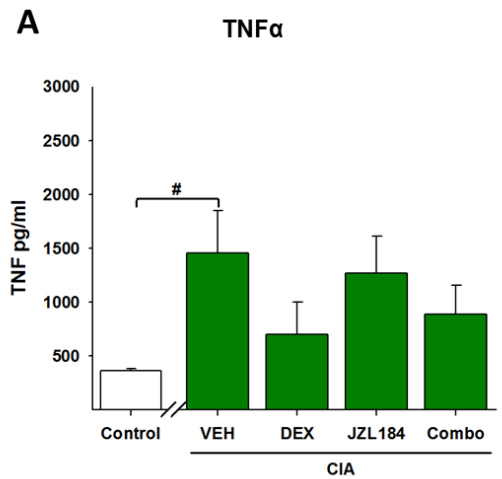

B

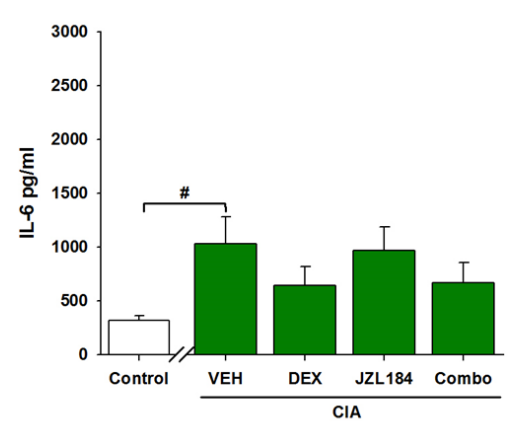

E

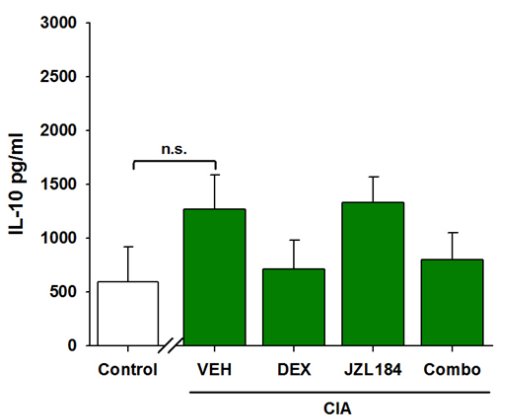

C

IL-6

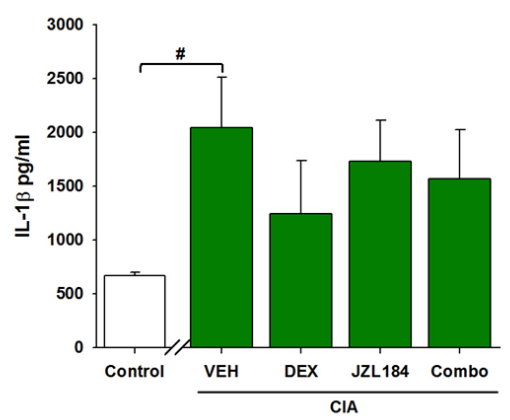

$\mathbf{F}$

MPO

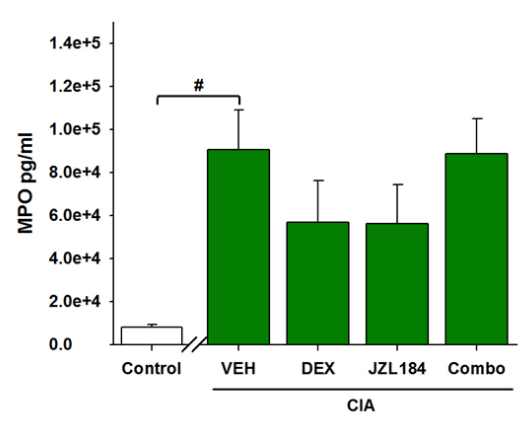

Figure 13. Repeated dual administration of JZL184/DEX did not affect CIA-induced increase in paw levels of proinflammatory cytokine (A-D) and MPO (F). Mice were administered the JZL184 (4 mg/kg; s.c.), DEX (0.015625 mg/kg; s.c.), a combination of JZL184 (4 mg/kg; s.c.) + $\operatorname{DEX}(0.015625 \mathrm{mg} / \mathrm{kg} ;$ s.c. $)$, or vehicle once daily for 19 days. CIA did not affect IL-10 levels (E). Data expressed as mean \pm SEM $(n=9-11) . * p<0.05$ vs. CIA mice; $\# \mathrm{p}<0.05$ vs. control mice. 


\section{Appendix A.}

\section{Grip strength as a measure of CIA-induced loss of paw function}

\section{$\underline{\text { Background }}$}

As proposed, the present study focused primarily on pain-induced behaviors such as mechanical allodynia (increased sensitivity to touch) or thermal hyperalgesia (increased sensitivity to noxious heat). These assays were chosen because they are among the most commonly used behavioral tests for pain induced by arthritis in rodents (Gao et al., 2015; Inglis et al., 2007b). That said, the vast majority of arthritis related reports focus exclusively on inflammation and not its resulting pain.

In addition, pain-induced behaviors are potentially problematic in that they are easily confounded by sedation. For example, mechanical allodynia is reversed by high dose opioids (Nagakura et al., 2003), which effectively sedate the test subject. On the other hand, painsuppressed behaviors are reversed when the animal increases its behavior, and are thus less susceptible to sedative confounds. Thus, the goal of this experiment was to examine a painsuppressed behavior as well as a test of functional ability, grip strength.

\section{$\underline{\text { Methods }}$}

Thirty male DBA1/J mice were subjected to CIA or control, as described in the main body of the document. Half of the CIA mice were repeatedly administered JZL184 (4 mg/kg, s.c.) or vehicle for 16 days. The inverted cage lid test (Brooks, Higgs, Jones, \& Dunnett, 2012) was used to measure grip strength. Mice were placed on the top of a wire cage bottom and the wire was briefly shaken to cause the mice to grip the wire. The wire was gently flipped upside-down along 
the mouse's y-axis (i.e., pitch, with the mouse's head going forward and down) and suspended approximately $20 \mathrm{~cm}$ above a cage filled with soft bedding. The latency for the mouse to drop from the wire was measured by a second experimenter using a stopwatch.

\section{$\underline{\text { Results }}$}

CIA treatment significantly decreased latency to fall $[F(2,27)=6.395 ; \mathrm{p}<.01$; Figure A1 $]$. Post hoc comparisons revealed that repeated JZL184 (4 mg/kg) treatment had no effect on grip strength.

\section{$\underline{\text { Discussion }}$}

The inverted cage lid test, a test of grip strength, was surprisingly effective at detecting CIA-induced loss of paw function. This low-tech alternative to allodynia and hyperalgesia tests has not been reported with CIA in mice, and offers some advantages over established pain models. The results align with a previous report indicating that CIA in rats attenuates grip strength as measured by the force used to grip a wire grid to resist the tail being pulled by a spring balance (Sasakawa, Sasakawa, Ohkubo, \& Mutoh, 2005). One advantage of the method used in the present study is that the test requires no special equipment and training is minimal.

Watching the mice cling to the wire lid, the differences between CIA and control mice was striking. Mice that had significant paw swelling, especially in the forepaws, had the shortest latencies to fall from the wire. Mice with overt swelling in both forepaws fell from the lid almost immediately. Conversely, mice without paw swelling were able to ambulate along the underside of the lid until they reached the maximum cutoff time of one minute. 
The idea to assess grip strength came about at the end of the present project, and so there was inadequate time to incorporate the test more broadly. So, this brief study was limited to only one test point in one cohort of CIA mice. Although MAGL inhibition had no effect on grip strength on day 16 , time course data may reveal a delay in functional loss. It may be informative to measure grip strength repeatedly over the course of CIA development, as a measure of functional loss of paw strength. 


\section{A Grip Strength Test}

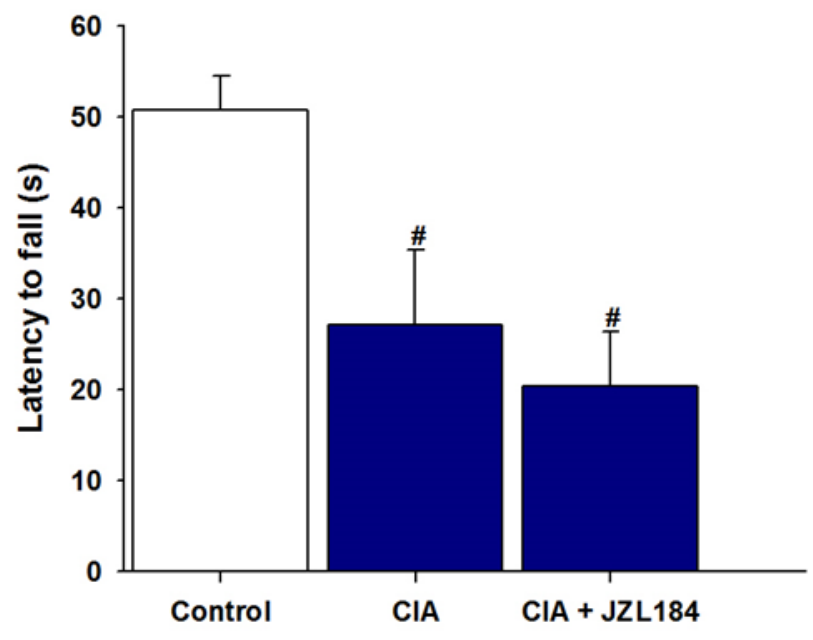

Figure A1. Collagen-induced arthritis (CIA) decreases grip strength. Mice were subjected to CIA. Mice were administered JZL184 (4 mg/kg, s.c.) or vehicle for 16 days, then grip strength was tested using the inverted cage lid test. Data expressed as mean \pm SEM $(n=10) . \# p<0.05$ vs. non-CIA control mice. 


\section{Appendix B.}

\section{Anti-arthritic effects of $\mathrm{CB}_{2}$ agonism in CIA and CFA-induced arthritis models}

\section{$\underline{\text { Background }}$}

The goals of the present study were (1) to evaluate the possible analgesic effects of the $\mathrm{CB}_{2}$ agonist HU-308 in collagen-induced arthritis (CIA) mouse model and (2) to compare the anti-inflammatory and analgesic effects of $\mathrm{CB}_{2}$ agonism by HU-308 in the CIA model of inflammatory arthritis and the complete Freund's adjuvant (CFA) model of inflammatory pain. There are a variety of selective $\mathrm{CB}_{2}$ agonists that have been synthesized to have a greater binding affinity for the $\mathrm{CB}_{2}$ receptor over the $\mathrm{CB}_{1}$ receptor. $\mathrm{CB}_{2}$ agonists provide an opportunity to harness the anti-inflammatory and analgesic effects of exogenous cannabinoids without the undesirable cognitive and behavioral side effects exhibited by more traditional cannabinoid agonists, such as THC (Hanus et al., 1999; LaBuda, Koblish, \& Little, 2005). Acute administration of $\mathrm{CB}_{2}$ agonists reduces pain and inflammation in several animal models of acute inflammatory pain, including intraplantar injection of CFA (Clayton, Marshall, Bountra, \& O'Shaughnessy, 2002; Kinsey et al., 2011a; Valenzano et al., 2005). However, despite the ability of CFA to induced chronic inflammatory pain that can last for weeks, the analgesic effects of $\mathrm{CB}_{2}$ agonism have not been evaluated beyond $48 \mathrm{~h}$ of inflammatory pain. Further, repeated administration of $\mathrm{CB}_{2}$ agonists reduces the inflammation and joint destruction caused by collagen induced arthritis (CIA) (Fukuda et al., 2014; Gui et al., 2015), but the analgesic effects are unknown. The present study tested the hypothesis that the $\mathrm{CB}_{2}$ selective agonist $\mathrm{HU}-308$ decreases inflammation and pain caused by CIA or CFA. 


\section{$\underline{\text { Collagen-induced arthritis }}$}

For the CIA model, male DBA1/J mice were immunized with an emulsion of collagen and CFA followed 21 days later by a secondary "booster" exposure to the collagen emulsion, to induce anti-collagen autoimmunity. On day 28 mice were administered $25 \mu \mathrm{g}$ lipopolysaccharide (LPS) in $0.1 \mathrm{ml}$ saline (ip) to "synchronize" arthritis induction (Caccese, Zimmerman, \& Carlson, 1992; Luo et al., 2011). CIA significantly increased paw swelling (i.e. arthritic clinical scores $[F(32,27)=8.794 ; \mathrm{p}<.01 ;$ Figure A2A $]$ and caliper measurements $[F(32,27)=4.136 ; \mathrm{p}$ $<.01$; Figure A2B $])$ and mechanical allodynia, per the von Frey test $[F(2,27)=12.728 ; \mathrm{p}<.01$; Figure A2C]. Repeated administration of the selective $\mathrm{CB}_{2}$ agonist HU-308 (3 mg/kg, i.p.) for 10 days significantly attenuated CIA-induced paw swelling. Surprisingly, HU-308 did not affect CIA-induced mechanical allodynia.

\section{$\underline{\text { CFA-induced arthritis }}$}

The CIA model is extensively used to research immunosuppressant treatments that reduce inflammation and disease progression in inflammatory arthritis. In contrast, intraplantar injection of inflammatory mediators is extensively used to characterize novel analgesic treatments for chronic inflammatory pain. To test this hypothesis, either complete Freund's adjuvant (CFA, $20 \mu \mathrm{l})$ or saline was injected directly into each hindpaw of male C57BL/6 mice to induce localized paw inflammation and pain. CFA significantly increased inflammatory pain and edema $24 \mathrm{~h}$ after administration $[F(6,21)=5.543 ; \mathrm{p}<.01$; Figure A2D $]$. Subchronic administration of HU-308 (50 mg/kg, i.p.) attenuated CFA-induced hyperalgesia, per the Hargreaves plantar stimulator test $[F(2,21)=7.464 ; \mathrm{p}<.01$; Figure A2E]. In contrast to the CIA model, HU-308 did not significantly affect CFA-induced paw edema. 


\section{$\underline{\text { Discussion }}$}

Taken together these results suggest a disconnect between the CIA model of inflammatory arthritis traditionally used to develop immunosuppresants and the CFA model of inflammatory pain used to develop novel analgesic treatments. The CFA model is an attractive alternative to the CIA model because of its relatively fast throughput. However, neither model reflects all aspects of inflammatory arthritis in humans, and the effects of the synthetic $\mathrm{CB}_{2}$ agonist HU-308 varied greatly between models. Although the present study provides new evidence that $\mathrm{CB}_{2}$ is a potential target for the development of new analgesic anti-inflammatory treatments for inflammatory arthritis these results may have reduced external validity and translatability. 


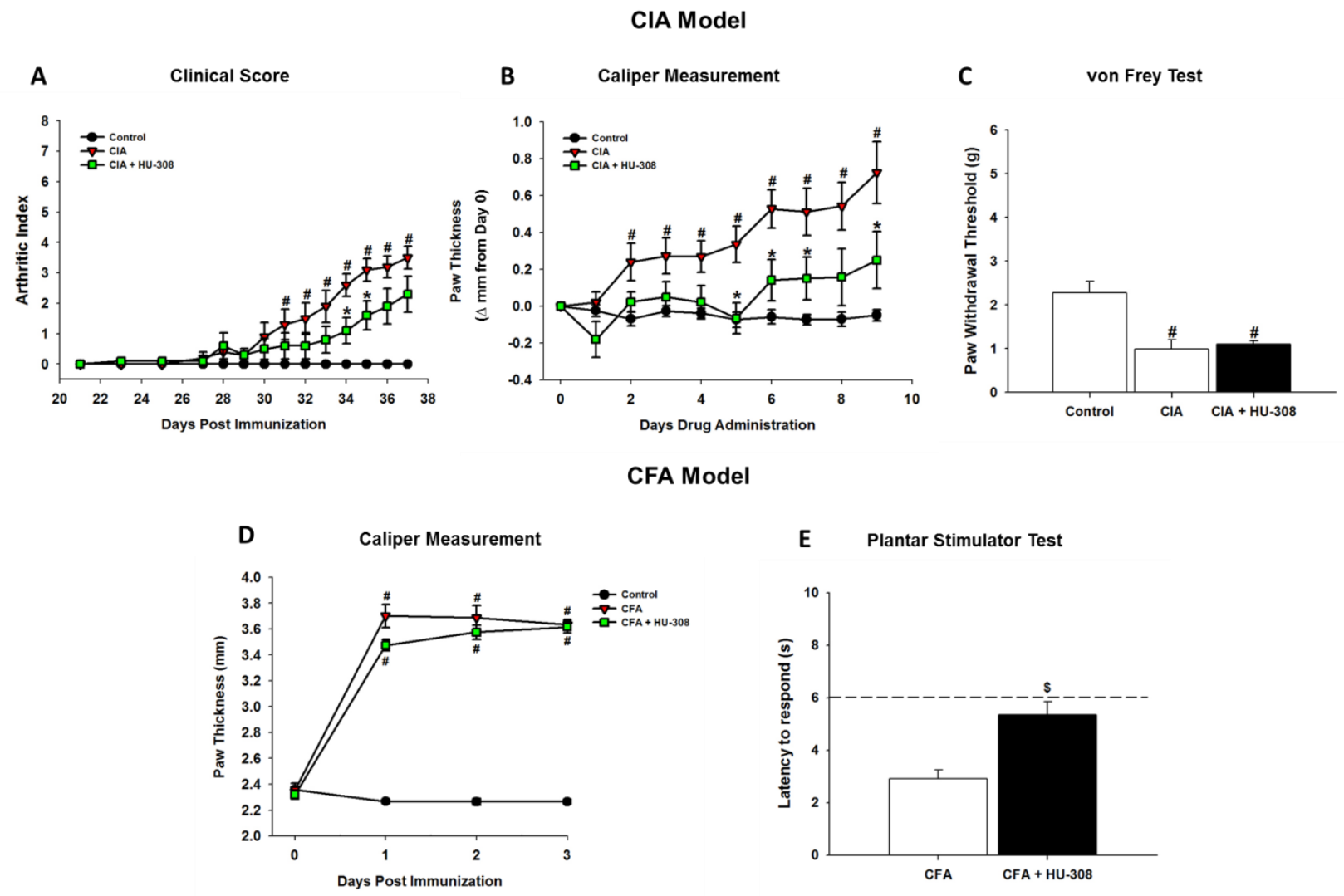

Figure A2. Disconnect between anti-inflammatory and analgesic effects of the $\mathrm{CB}_{2}$ agonist $\mathrm{HU}$ 308 in the CIA model of inflammatory arthritis and the CFA model of inflammatory pain. To test the effects of HU-308 in a model of inflammatory arthritis mice were subjected to CIA and administered HU-308 (3 mg/kg, i.p.) for 10 days. HU-308 attenuated CIA-induce paw swelling as measured by clinical scores (A) or paw thickness (B). HU-308 did not affect CIA-induced mechanical allodynia (C). A separate group of mice was injected in the hind paw with CFA and administered HU-308 (50 mg/kg, i.p.) for 4 days. HU-308 reduced CFA-induced edema, but did not attenuate CFA-induced hyperalgesia (D). Data expressed as mean \pm SEM $(\mathrm{n}=8-10) .{ }^{*} \mathrm{p}<$ 0.05 vs. CIA; $\$$ p < 0.05 vs. CFA; \# p < 0.05 vs. control mice. Dotted line represented control saline paw latencies. 


\section{Appendix C.}

\section{Collagen Antibody-induced Arthritis model}

\section{$\underline{\text { Background }}$}

The goal of the present study was to pilot the collagen antibody induced arthritis (CAIA) model of inflammatory arthritis in the lab. The production of antibodies against self-peptides (e.g., rheumatoid factor, anti-citrullinated protein, and collagen) by B cells of the adaptive immune system are important in the pathogenesis of both RA and CIA (Asquith et al., 2009; Takemura et al., 2001). In the CAIA model, anti-collagen antibodies generated from mice are passively transferred to test mice to induce paw swelling and pain (Frolov, Yang, Dong, Hammock, \& Crofford, 2013; Terato et al., 1992).

The CAIA model of inflammatory arthritis has several advantages and disadvantages over the more classical CIA model. For example, CAIA develops much faster than CIA (e.g., arthritis develops in one or more paws in two weeks, as opposed to five weeks with CIA). Further, unlike CIA, which can only be induced in susceptible mice with certain haplotypes of the major histocompatibility complex (MHC) class II genes, CAIA can be induced in a wide variety of mice strains (Asquith et al., 2009). This flexibility allows researchers to study inflammatory arthritis using genetic tools, such as gene knockout and transgenic mice that are typically backcrossed on the non-CIA susceptible C57BL/6 mouse strain.

On the other hand, although the CAIA model has a quicker throughput compared to CIA, arthritis induction is exceedingly more expensive in the CAIA model and the shorter timeline might not translate as well to human chronic inflammatory arthritis (Khachigian, 2006). In addition, CAIA inflammation is mainly perpetuated by the innate immune response and lacks the 
critical adaptive T cell immune response needed to perpetuate CIA and RA (Asquith et al., 2009; Kagari et al., 2002). The present study tested the hypothesis that CAIA would induce paw swelling and pain-related behaviors that would be attenuated by the MAGL inhibitor JZL184 (4 $\mathrm{mg} / \mathrm{kg})$.

\section{Methods}

Male BALB/c mice were administered a cocktail of anti-collagen antibodies or saline via tail vein injection, per manufacturer's protocol (Chondrex, Redmond, WA). Three days later, mice were administered lipopolysaccharide (LPS, $50 \mu \mathrm{g}$, i.p.) to stimulate the immune response. Mice were administered JZL184 (4 mg/kg, s.c.) or vehicle (1:1:18 parts ethanol, cremophor, and normal saline) once daily for 15 days. Mice were assessed daily for arthritis, including clinical scoring and paw thickness. On the 15 th day after immunization, mice were tested for mechanical allodynia and thermal hyperalgesia, as detailed in the main body of the dissertation.

\section{$\underline{\text { Results }}$}

CAIA did not significantly affect paw swelling (i.e., arthritic clinical scores $[F(2,24)=2.161 ; \mathrm{p}$ $=.1371$; Figure A3A $]$ and caliper measurements $[F(2,24)=1.411 ; \mathrm{p}=.2634$; Figure A3B $]$ ) or thermal hyperalgesia $[F(2,24)=.482 ; \mathrm{p}=.6233$; Figure A3D $]$. However, CAIA did induce mechanical allodynia, per the von Frey test $[F(2,24)=4.654 ; \mathrm{p}<.05$; Figure A3C $]$. Repeated JZL184 had no effect on paw swelling or pain-related behaviors.

\section{$\underline{\text { Discussion }}$}

These results suggest that although the CAIA model is broadly reported to be easier to induce than the CIA model of inflammatory arthritis, the CAIA model, like CIA, still has optimization problems. Although consultation with the vendor did not yield any obvious 
problems with our induction methodology, it is likely we had slight issues not written in published protocols that led to a lower incidence. It is suggested that delivering the antibodies via tail vein injection, versus intraperitoneal injection, produces optimal CAIA incidence (Khachigian, 2006). Thus, it is possible that some mice accidently received a subcutaneous tail injection, which is the least effective method of delivering CAIA. This is unlikely, given that I was thoroughly trained by the Office of Laboratory Animal Resources to inject into the tail vein, a procedure that I practiced extensively prior to injecting collagen antibodies. Moreover, I observed the injection sites for tell-tale blisters that form when injecting subcutaneously or intradermally, and observed neither phenomenon. Nevertheless, my opinion is that, with optimization, CAIA is a promising model to develop novel treatments for inflammatory arthritis. 
A

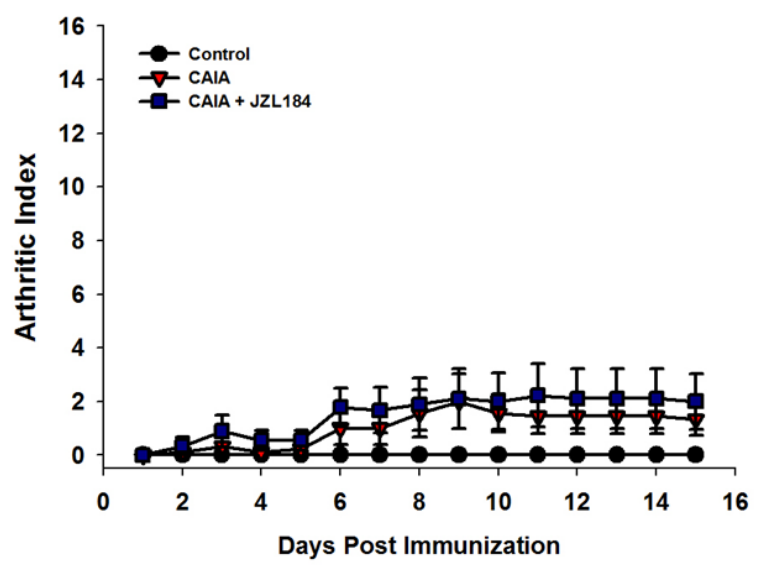

C

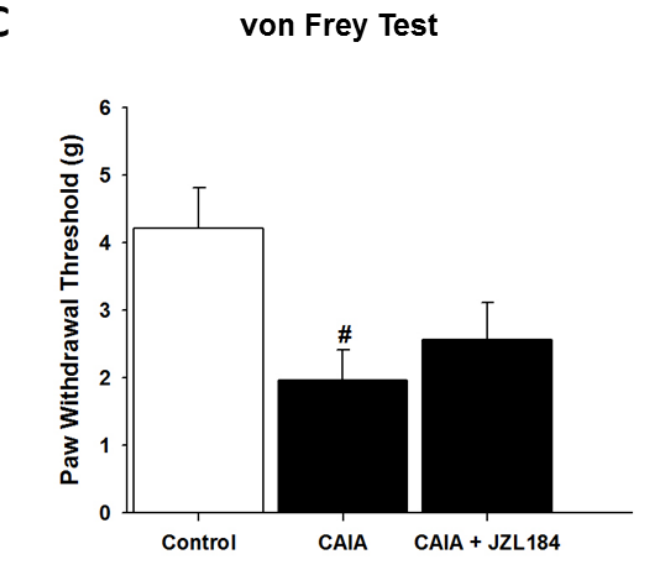

B Caliper Measurement

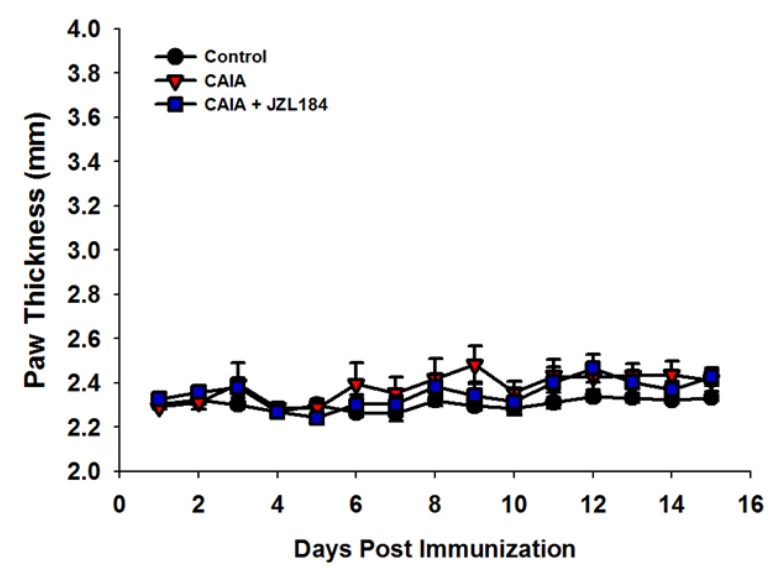

D Plantar Stimulator Test

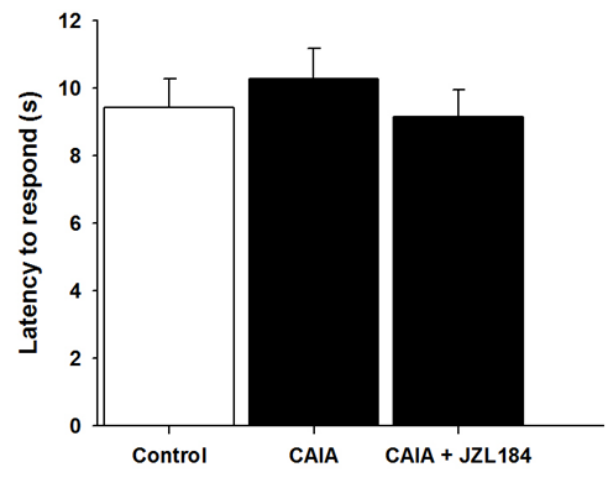

Figure A3. CAIA induced mechanical allodynia, but not paw swelling. Mice were administered an anti-collagen antibody cocktail to induce CAIA or saline via tail vein injection. Three days later mice were administer $50 \mu \mathrm{g}$ of LPS. Mice were JZL184 (4 mg/kg; s.c.) or vehicle once daily for 15 days. CAIA did not induce paw swelling compared to non-CAIA controls as measured by clinical scores (A) and calipers (B). CAIA induced mechanical allodynia in the von Frey assay (C), but not thermal hyperalgesia in the plantar test (D). JZL184 (4 mg/kg) did not affect paw swelling, allodynia, or hyperalgesia. Data expressed as mean $\pm \operatorname{SEM}(n=9)$. \# $\mathrm{p}<$ 0.05 vs. control mice. 